\title{
A Review on Synthesis of Nitrogen-Containing Heterocyclic Dyes for Textile Fibers - Part 2: Fused Heterocycles
}

\author{
Tawfik A. Khattab ${ }^{1^{*}}$ and Mohamed Rehan ${ }^{2}$ \\ ${ }^{1}$ Dyeing, Printing and Auxiliaries Department, Textile Industries Research Division, \\ National Research Centre, 33 El-Buhouth Street, Dokki, Cairo 12622, Egypt. \\ ${ }^{2}$ Department of Pretreatment and Finishing of Cellulosic Fibers, Textile Industries \\ Research Division, National Research Centre, 33 El-Buhouth Street, Dokki, Cairo \\ 12622, Egypt.
}

\begin{abstract}
MPORTANCE of heterocyclic dyes has recently increased due to their deep shades, high tentorial strength, excellent colorfastness and brightness compared to azobenzene analogous. Development of novel synthetic approaches for fused heterocyclic dyes has remained a highly interesting but challenging proposition. An overview of the application of nitrogen-containing fused heterocyclic dyestuffs for textile coloration is presented. In this review, we provide details outlining the synthesis of recently prepared fused nitrogen-containing heterocyclic dyestuffs and their dyeing efficiency on textile fibers.
\end{abstract}

Keywords: Heterocycles, Dyestuffs, Textiles, Synthesis, Coloration.

\section{Introduction}

Dyes have been used as natural and synthetic products for a variety of applications, such as inkjet printing, plastics, textile coloration, adhesives, beverages, ceramics, photography, cosmetics, foodstuff, optoelectronics, coatings, sensors, xerography, constructions and biomedical applications [1-14]. Heteroaromatic compounds have been used in various fields of life sciences and technology [15-21]. Numerous of heterocyclic dyes are now commercialized to produce a full range of dyestuffs especially for textile coloration. Dyestuffs that are employed for textile coloration often come with especial properties including high colorfastness to sublimation, light, washing, perspiration and crocking. Oil crisis in 1970s led to a sharp increment in costs of raw materials for production of dyestuffs. This created a force toward lower cost dyestuffs by enhancing the production procedures and by replacing dyes of low color strength, such as anthraquinone derivatives, with higher color strength dyes, such as heterocyclic dyes [22-28].

In continuation to the first part of this review which discussed the synthesis of five and sixmembered nitrogen-containing heterocyclic dyestuffs for textile coloration, herein, we describe the advances outlining the synthesis of fused nitrogen-containing heterocyclic dyes and their application on textile fibers

Fused nitrogen-containing heterocyclic dyes

Dyestuffs based on 4-aminoazobenzene, such as 9-phenylazoJulolidines $\mathbf{1}$ and 8-phenylazolilolidine 2 (Fig. 1), exhibited notable bathochromic shifts, comparative to 4-dialkylaminoazobenzenes, those bathochromic shifts were accompanied by considerable drop in light fastness. The inclusion of a carbonyl group into julolidine-based molecular frameworks $\mathbf{3}$ resulted in enhanced light fastness. However, such ketojulolidine-based dyestuffs are usually not appropriate for transfer printing. The existence of a cyanoethyl group 4 (Fig. 1) $\left(\mathrm{Y}=-\mathrm{CH}_{2} \mathrm{CH}_{2} \mathrm{CN}\right)$ brings about moderate improvement in light fastness.

$N$-ethyl-1,2,3,4-tetrahydroquinoline was prepared via quaternization of $1,2,3$, 4-tetrahydroquinoline employing iodoethane, followed by dealkylation using sodium azide in dimethylformamide. Trifluoroacetylation of 1,2,3,4-tetrahydroquinoline was accomplished using a solution of trifluoroacetic anhydride in

*Corresponding author e-mail: tkhattab@kent.edu 
tetrachloromethane. Trifluoroacetyl was subjected to reduction using diborane in tetrahydrofuran, and the mixture was then refluxed for 21 hours. Aromatic diazonium salts were then gradually added to a well-stirred dispersion of $N$-ethyl-1,2,3,4-tetrahydroquinoline or $N$-2, 2, 2-trifluoroethyl-1, 2, 3, 4-tetrahydroquinoline, respectively, in an aqueous acetic acid solution containing sodium acetate and kept at $0^{\circ} \mathrm{C}$. Successful azo-coupling between trifluoroethyl derivative and weakly electrophilic diazonium ions only took place in methylene chloride with the assistance of sodium dodecylbenzenesulfonate using phase transfer method.
Trifluoroethyl dyes 4 and 5 (Fig. 1) $\left(\mathrm{X}=\mathrm{CH}_{3}\right.$, $\mathrm{H}, \mathrm{Cl}, \mathrm{Br}, \mathrm{CF}_{3}, \mathrm{COCH}_{3}, \mathrm{CN}, \mathrm{NO}_{2} ; \mathrm{Y}=\mathrm{C}_{2} \mathrm{H}_{5}$, $\mathrm{CH}_{2} \mathrm{CF}_{3}$ ) have rather different colors from their ethyl analogues. Both series are appropriate for transfer printing and possess satisfactory colorfastness to wash on polyester and moderate on nylon. $N$-ethyl derivatives have better light fastness than their julolidine counterparts. When compared with $N$-ethyl dyestuffs, the trifluoroethyl derivatives displayed substantial enhancement in light fastness on both polyester and nylon. Light fastness was relying on substituents linked to the terminal nitrogen and is generally enhanced by electron withdrawing substituents [29].

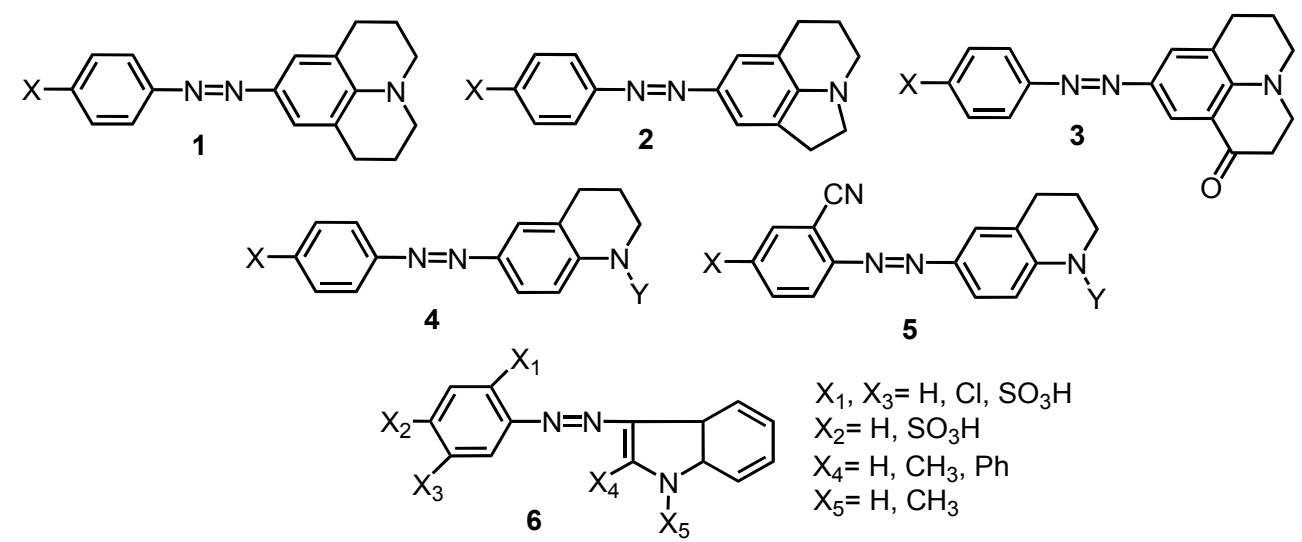

Fig. 1. Chemical structure of the Reactive dyes and dyes based on 4-aminoazobenzene.

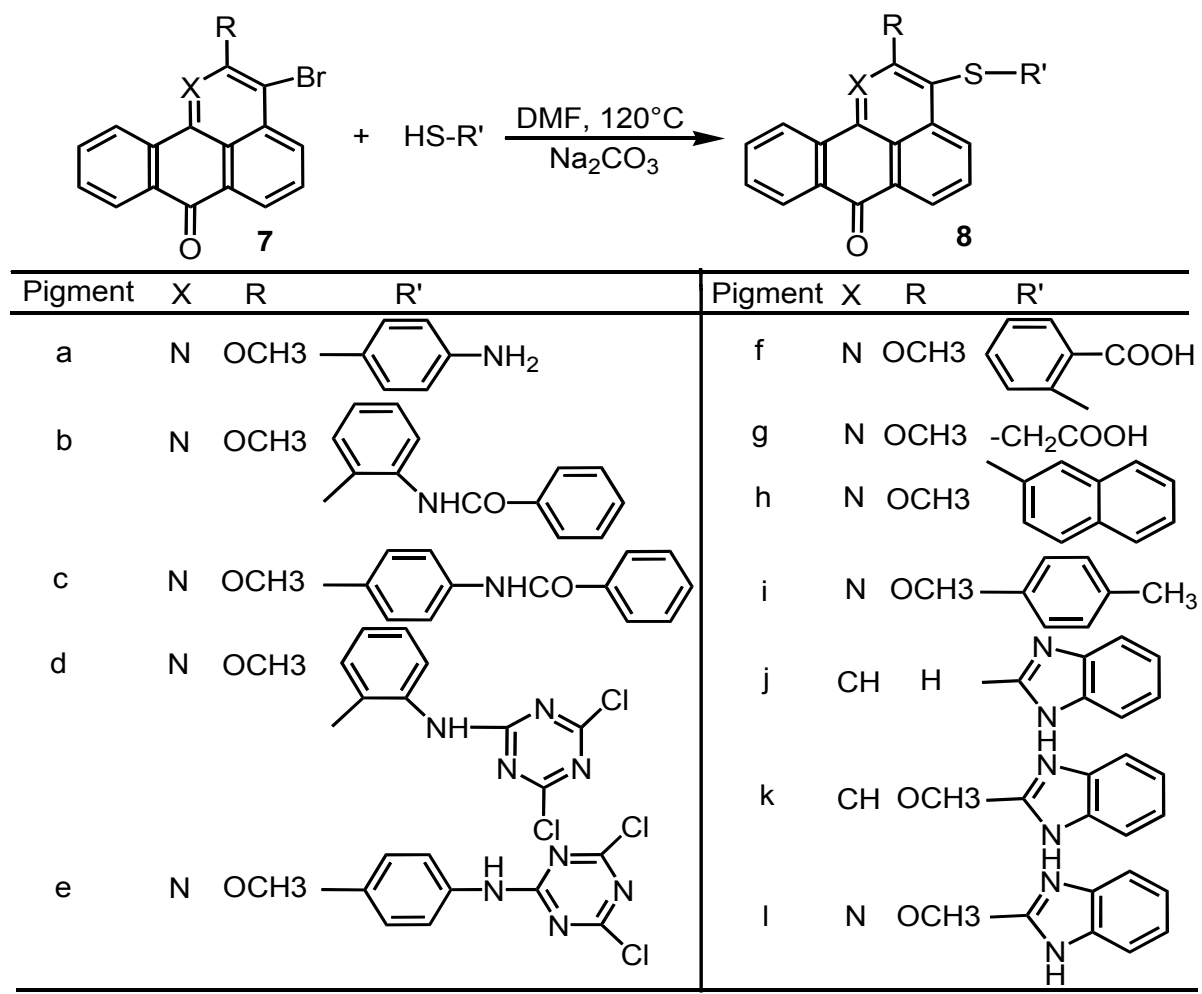

Scheme 1. (top) and Table 1 (bottom) for 1-azabenanthrone derivatives. 
Arylazoindole sulfonic acid dyes 6 have been synthesized using a mixture of glacial acetic acid and dimethylformamide as solvent for the azocoupling process.

The tinctorial properties of 6 (Fig. 1) on both natural and synthetic fibers were generally very good. Washing and light fastness properties were evaluated from poor to very good for wool and fairly good for nylon substrates [30].

Daylight fluorescent pigments based on benzanthrone and 1-azabenanthrone $\mathbf{8}$ were prepared by condensation of 7 with thiophenols in DMF and in presence of sodium carbonate via refluxing for 2 hours to yield $\mathbf{8 a - 1}$ (Scheme 1) and (Table 1).

The pigments 8a-l (Table 1) showed very bright yellow to greenish-yellow shades and high tinctorial strength especially on polyester fibers. The pigments displayed good thermal stability, while the light fastness was ranged between poor to very good [31].<smiles>O=C1Nc2cccc3cccc1c23</smiles>

9<smiles>O=C1Nc2ccccc2C1=O</smiles>

$10 \mathrm{H}$

Compound $\mathbf{9}$ was converted into $\mathbf{1 1}$ via reaction with phosphorus oxychloride. Condensation with 6-methoxythioindoxyl resulted in red dye, while 2-cyano-4-nitroaniline yielded brilliant yellow dyestuff (Scheme 2). Condensation of 9 with ethyl-5-pyrazolone-3-carboxylate has been described in the Color Index as C.I. Disperse Red 196. Compounds 12 were utilized as coupling components for preparation of azo disperse dyes with yellow to orange shades. Violet to bluishviolet disperses dyes 13a-k (its resonance form is 14) was prepared by condensation of 9 with 12 in presence of phosphorus oxychloride and in refluxing benzene for 5 hours (Scheme 2). Similar condensations of $\mathbf{1 0}$ with $\mathbf{1 2 c}, \mathbf{e}, \mathbf{f}, \mathbf{i}$ yielded violet disperse dyes $\mathbf{1 6} \mathbf{c}, \mathbf{e}, \mathbf{f}, \mathbf{I}$ (the resonance forms are $\mathbf{1 5}$ and 17). Substituents on the nitrogen heteroatom of the homophthalimide moiety greatly influenced the sublimation fastness which was rated between 2-3 for 16c,i and 13d,e,h,k, 3-4 for 16e,f and $\mathbf{1 3 b}, \mathbf{g}$, and 4-5 for 13a,c,f,I,j. In general, all dyes showed poor light fastness on polyester fibers [32] (Scheme 2).<smiles>ClC1=Nc2cccc3cccc1c23</smiles>

11<smiles>[R]N1C(=O)Cc2ccccc2C1=O</smiles>

12

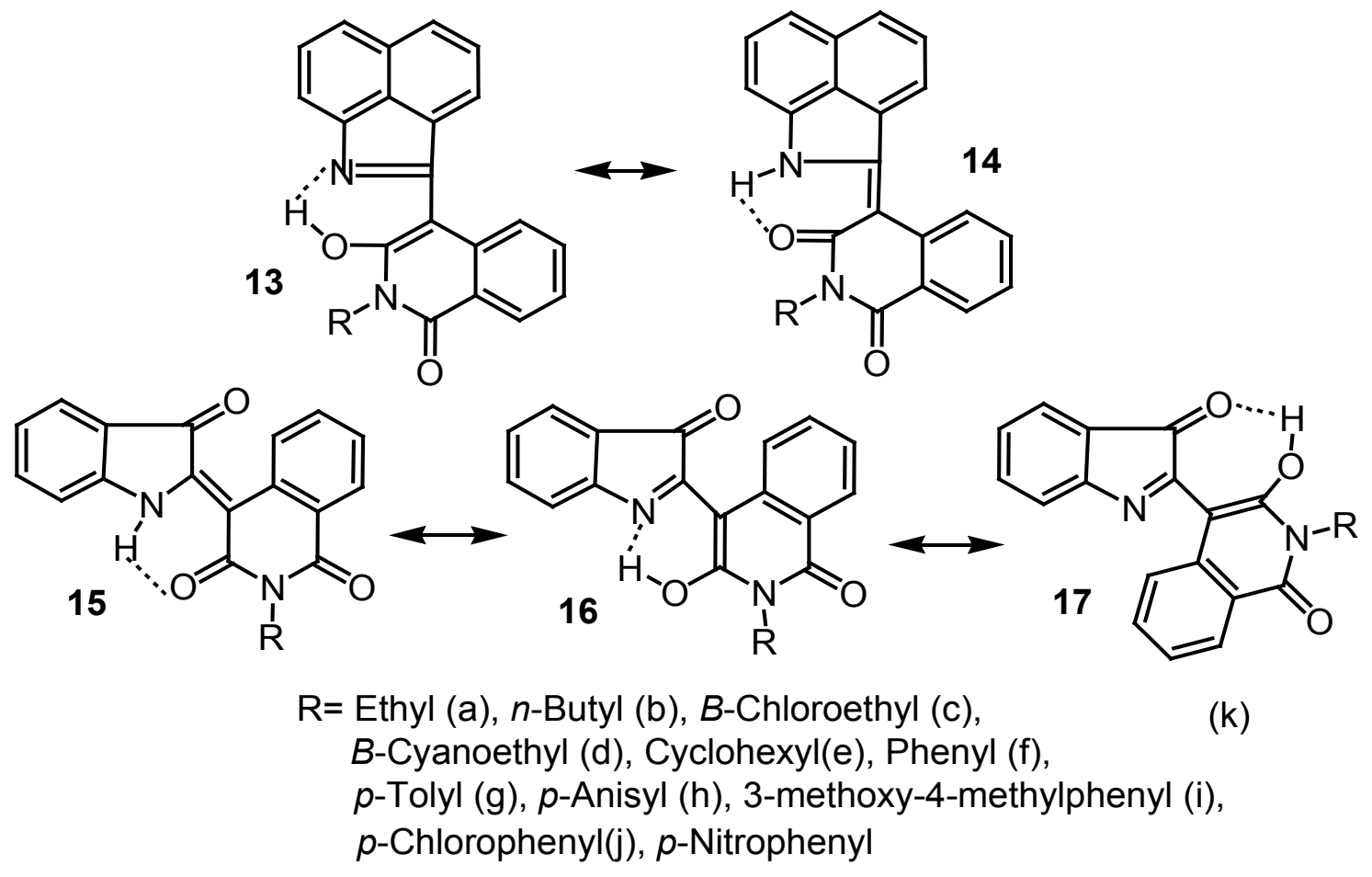

Scheme 2. Sunthankar and co-workers developed a method to prepare 1-amino-4-substituted-2-bromoanthraquinones.

Egypt. J. Chem. 61, No.6 (2018) 


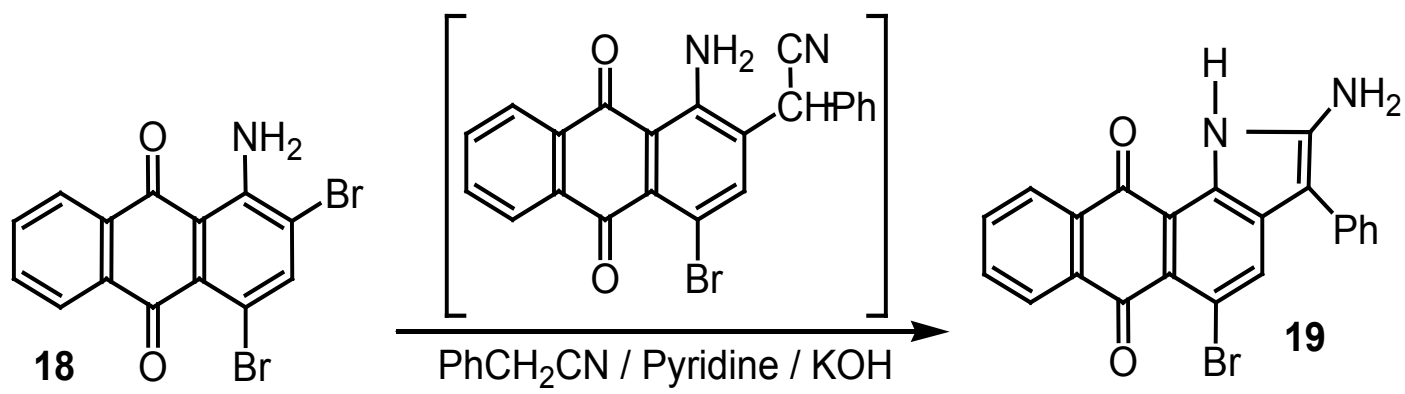

Scheme 3. Compound 18 was reacted with benzyl cyanide under alkaline conditions to yield 19 (Scheme 3). Benzoylation of 19 was occurred by refluxing anthraquinonepyrroles with benzoyl chloride for 1 hour in chlorobenzene as a solvent.

Dyes were applied on polyester as disperse dyes. Shades were tinctorially weak and light fastness was also poor [33].

4-Chloro-1, 8-naphthalic anhydride was condensed with pyrrolidine and Imidazole in diethyleneglycol dimethyl ether, and with piperidine and piperazine in 2-methoxyethanol, to give 20, 21, 22 and 25, respectively (Scheme 4). Compound $\mathbf{2 2}$ was then refluxed in a mixture of glacial acetic acid and acetic anhydride for 1 hour to yield $\mathbf{2 3}$.

Compound $\mathbf{2 4}$ was obtained from 3-amino-1, 8-naphthalic anhydride by Skraup synthesis. Similar reaction starting from 4-amino-1, 8-naphthalic anhydride afforded pyrido[2,3-c]-1,8-naphthalic anhydride which was obtained by oxidation of pyrido[2,3-c] acenaphthene. Compound $\mathbf{2 0}$ was refluxed with 3-methoxypropylamine in ethanol, and with arylamines in 2-methoxyethanol, for 1 hour to give 20 ( $\mathrm{R}=N$-3-methoxypropyl). Other imides were similarly prepared from $\mathbf{2 1}, \mathbf{2 2}, \mathbf{2 4}$ and $\mathbf{2 5}$. A mixture of $\mathbf{2 1}$ and 4-chloro-o-phenylenediamine was refluxed for 1.5 hour in glacial acetic acid to give an isomeric mixture of 3-(and 4-) piperidino10 (and 11)-chloro-7H-benzimidazo[2, 1-a] benz[d, e]isoquinolin-7-one 28. Similarly, other analogous derivatives were prepared including 27, 29, 30, 31 and 32 (Scheme 4).

The replacement of 4-chloro group in naphthalic anhydrides was assisted by additional electron withdrawing nitro group. The 4-chloro3-nitro-1, 8-naphthalic anhydride was interacted in ethyl alcohol with pyrrolidine, piperidine and piperazine, while imidazole reacted well in 2-methoxyethanol, and diethyleneglycol dimethylether was used with pyrazole. 3-Nitro-4- piperidino-1,8-naphthalic anhydride was refluxed with aniline in ethanol to yield 3-nitro-4-piperidino$\mathrm{N}$-phenyl-1,8-naphthalimide. Similarly, 3-nitro4-pyrrolidino-, 3-nitro-4-piperidino-, 3-nitro-4piperazino-, 3-nitro-4-imidazolo-, and 3-nitro-4pyrazolo-1,8-naphthalimides $\mathbf{3 3}$ were prepared. The benzimidazo derivatives were synthesized as in the case of the unnitrated analogues.

Compound 24 and 4-methoxy-ophenylenediamine was refluxed for 1 hour in chlorobenzene, while dimethyl sulfate was added to produce the corresponding quaternary salts of pyrido[2,3-c]-7H-benzimidazo[2, 1-a]benz[d, e] isoquinolin-7-ones.

Imides and benzimidazoles substituted by cyclic tert-amino groups on the naphthyl moiety were generally good dyestuffs for synthetic fibers. Light fastness was moderate to good for 4-piperidino derivatives and poor to moderate for 4-pyrrolidino dyestuffs. 4-Piperazino derivatives exhibited poor light fastness. Colorfastness to sublimation of dyestuffs was mainly good, tending to be better with increased both mass and polarity of benzimidazoles. Nitrated analogues colored polyester in deep yellow (for imides) to orange shades (for benzimidazoles). The depth of shade was mainly good and mostly better than that of unnitrated dyestuffs. Sublimation fastness was generally of high order whilst the light fastness was noticeably decreased compared to the unnitrated derivatives and none of these dyestuffs had acceptable light fastness [34].

3-Amino and 4-amino-1, 8-naphthalic anhydrides was diazotized in nitrosylsulphuric acid and coupled with $N-\beta$-cyanoethyl- $N-\beta-$ hydroxyethylaniline. These intermediates were then acetylated by reflux for 30 minutes in a 
mixture of acetic anhydride and acetic acid. These intermediates, and their $o$-acetylated derivatives, were subjected to condensation with alkylamines and arylamines to give dyestuffs $\mathbf{3 4}$, some of which were also produced by diazotization of 4-amino-1, 8-naphthalimides and azo-coupling to $N$ - $\beta$-cyanoethyl- $N$ - $\beta$-hydroxyethylaniline or its $o$-acetyl analogue. Similar condensation with $o$-phenylenediamines gave dyestuffs 35 (Scheme 5). For dyes 35, derived from $N$ - $\beta$-cyanoethyl$N$ - $\beta$-hydroxyethylaniline, condensation was favorably effective in 2-methoxyethanol followed by ring-closure in situ of the resulting imide by addition of anhydrous zinc chloride.

Imides and imidazoles are excellent dyestuffs for synthetic fibers affording yellow-orange to bluish-red shades. Colorfastness to both light and sublimation, especially for 4-phenylazo substituted analogues, is very good [35].

Unsymmetrical disazo 36 and trisazo 37 was applied as acid and direct dyes on wool and cotton fabrics. They had fairly good washing fastness but unsatisfactory tinctorial strength and light fastness below average was monitored [36] (Scheme 6).<smiles>[R]N1C(=O)c2cccc3c(N4CCCC4)ccc(c23)C1=O</smiles><smiles>[X]CCN(CCC)c1ccc2c3c(cccc13)C(=O)N([R])C2=O</smiles><smiles></smiles><smiles>[R]N1C(=O)c2cccc3c(-n4ccnc4)ccc(c23)C1=O</smiles><smiles>[R]N1C(=O)c2cccc3c(-n4cccn4)c([N+](=O)[O-])cc(c23)C1=O</smiles>

$21 \mathrm{X}=\mathrm{CH}_{2}$ 25

$23 \mathrm{X}=\mathrm{N} \cdot \mathrm{COCH}_{3}$

$\mathrm{R}=\mathrm{H},\left(\mathrm{CH}_{2}\right)_{2} \mathrm{CH}_{3},\left(\mathrm{CH}_{2}\right)_{3} \mathrm{OH},\left(\mathrm{CH}_{2}\right)_{3} \mathrm{OCH}_{3}, \mathrm{Ph}, \mathrm{C}_{6} \mathrm{H}_{4} . \mathrm{OCH}_{3}-p$, $\mathrm{OCH}_{3}, \mathrm{Cl}$, Cyclohexane, $\mathrm{CH}_{2} \mathrm{Ph}, \mathrm{CH}_{3}, \mathrm{Br}, \mathrm{NO}_{2}$<smiles>O=c1c2cccc3c(N4CCCC4)ccc(c32)c2nc3ccccc3n12</smiles>

27<smiles></smiles>

$28 X=\mathrm{CH}_{2}$

$29 \quad X=\mathrm{NH}$

$30 \mathrm{X}=\mathrm{N} . \mathrm{COCH}_{3}$<smiles></smiles>

31<smiles></smiles>

32<smiles></smiles>

33

Scheme 4. 4-Chloro-l, 8-naphthalic anhydride was condensed with pyrrolidine and Imidazole in diethyleneglycol dimethyl ether, and with piperidine and piperazine in 2-methoxyethanol, to give 20, 21, 22 and 25, respectively (Scheme 4). Compound 22 was then refluxed in a mixture of glacial acetic acid and acetic anhydride for 1 hour to yield 23. 
<smiles>[X]OCN(CCN)c1ccc(N=Nc2cccc3c2-c2cccc(c2)C3=O)cc1</smiles>

$\mathrm{R}=\mathrm{H}, \mathrm{C}_{3} \mathrm{H}_{6} \mathrm{OH}, \mathrm{C}_{3} \mathrm{H}_{6} \mathrm{OCH}_{3}, \mathrm{C}_{3} \mathrm{H}_{6} \mathrm{OBu}$, $\mathrm{CH}_{2} \mathrm{Ph}, \mathrm{Ph}, \mathrm{C}_{3} \mathrm{H}_{6} \mathrm{OAc} ; \mathrm{X}=\mathrm{H}, \mathrm{Ac}$

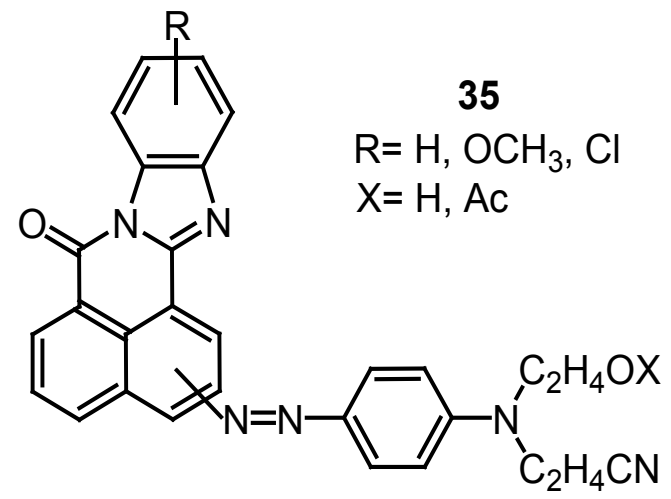

Scheme 5. Imides and imidazoles are excellent dyestuffs for synthetic fibers affording yellow-orange to bluish-red shades. Colorfastness to both light and sublimation, especially for 4-phenylazo substituted analogues, is very good [35].<smiles></smiles>

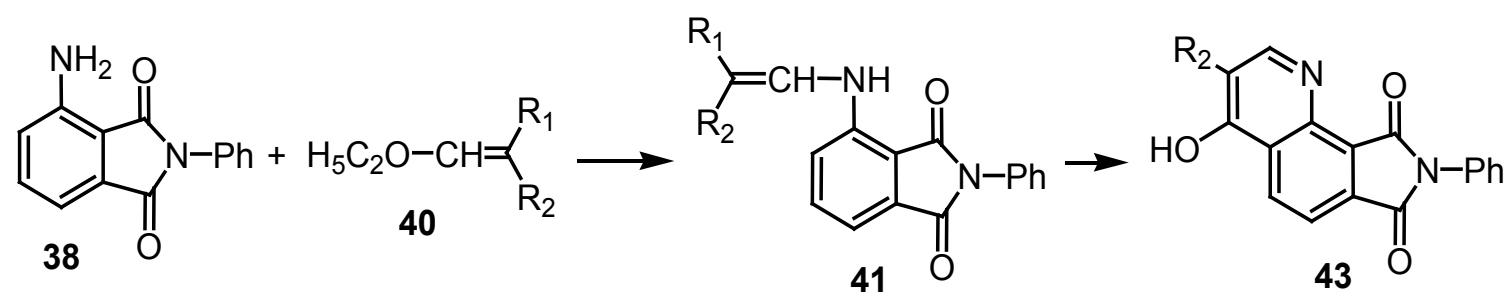<smiles>[R]C([R])=CCNc1ccc2c(c1)C(=O)N(c1ccccc1)C2=O</smiles>
39

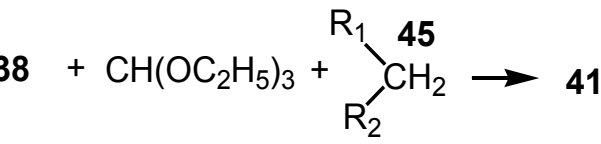

$39+\mathrm{CH}\left(\mathrm{OC}_{2} \mathrm{H}_{5}\right)_{3}+45 \rightarrow 42$

41,42 I $\mathrm{R}_{1}=\mathrm{COOC}_{2} \mathrm{H}_{5} ; \mathrm{R}_{2}=\mathrm{COOC}_{2} \mathrm{H}_{5}, \mathrm{CN}, \mathrm{COCH}_{3}$

41', 42' / $\mathrm{R}_{1}=\mathrm{Ph}$,<smiles>N#C[R]#[Fe]c1nc2ccccc2[nH]1</smiles>

Scheme 6 
The fusion of 3(and 4)-nitrophthalic anhydride with aniline gave 3(and 4)-nitro-1- $N$ phenylphthalimide $[37,38]$ which was exposed to reduction using tin(II) chloride and hydrochloric acid to afford the corresponding amino derivatives $\mathbf{3 8}$ [39] and 39 [40]. Compound $\mathbf{4 0}$ was condensed with 38 and 39 respectively, by refluxing for 8 hours in dry xylene and in addition to a drop of piperidine, to give $\mathbf{4 1}$ and $\mathbf{4 2}$. In a second method, $\mathbf{3 8}$ and $\mathbf{3 9}$ was reacted in situ with ethyl orthoformate and an appropriate active methylene or methyl group-containing compounds $\mathbf{4 5}$, in refluxing xylene for 3 hours to yield 41' and 42', respectively. Compounds $\mathbf{4 1}$ and 42 were refluxed for 7-10 hours in Dowtherm A toward effective cyclization affording 43 and 44 (Scheme 6).
Most compounds have shades from pale to bright yellow in color and they were applied as fluorescent dyestuffs on polyester fibers giving light greenish-yellow to bright yellow shades with poor to moderate pick-up. The resulting dyeing had moderate colorfastness to both light and sublimation [41].

Compound 50 (Scheme 7) was synthesized from 46 and then converted to $\mathbf{5 1}$ which were coupled with $\mathbf{5 2}$ in acidic medium, and with 52' in alkaline medium to give 53. Compound 54 was diazotized and coupled with $\mathbf{5 0}$ in acidic medium affording $55\left(\mathrm{R}_{1}=\mathrm{H} ; \mathrm{R}_{2}=\mathrm{CH}_{3} ; \mathrm{R}_{3}=\mathrm{H}\right)$, which was acetylated by reflux for 4 hours in acetic anhydride to provide 6-acetamido-5-(4-methylphenyl)azo2-methoxyquinoxaline dye (Scheme 7).<smiles>COc1cnc2cc(N)ccc2n1</smiles>

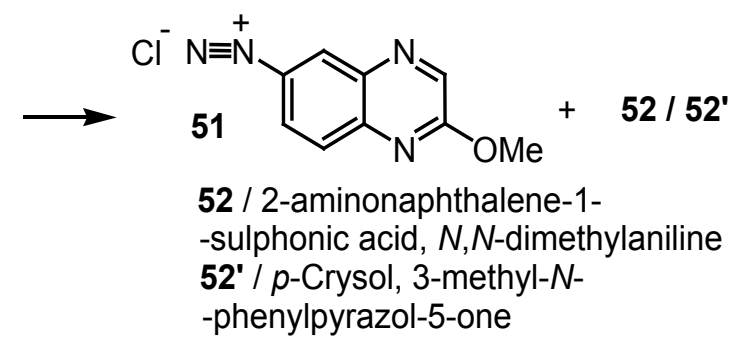

Scheme 7

Disperse dyes $\mathbf{5 3}$ and $\mathbf{5 5}$ gave good coloration on polyester, affording deep yellow to red shades. The brightness of shade was particularly apparent for all derivatives except $53(\mathrm{R}=2$-hydroxy-5methylphenyl $)$ and $\mathbf{5 5}\left(\mathrm{R}^{1}=o-\mathrm{CH}_{3} ; \mathrm{R}^{2}=\mathrm{CONHPh}\right.$; $\mathrm{R}^{3}=\mathrm{CH}_{3}$ ) (Scheme 8). Disperse dye 53 gave excellent fastness to light, whereas $\mathbf{5 5}$ have moderate light fastness. Fastness to sublimation of all dyeings was generally very good [42].

Condensation of 56,63 or 68 with bifunctional reagent $\mathbf{5 7}$ in dimethylformamide containing pyridine at reflux for 4-5 hours, gave the corresponding pyridobenzoimidazole 58, 64 and 69. Moeckli [43] described the cyanation at the 4-position of coumarins containing negative functional substituents at the 3-position. Accordingly, the benzimidazoles 58, 64 and
69 and sodium cyanide were stirred together in dimethylformamide at room temperature for 4 hours (30 hours in case of 58) followed by addition of bromine at $0-5^{\circ} \mathrm{C}$ to produce 59,65 and 70.

Similarly, we can obtain 67 from 64 using only 1 mole of bromine instead of 2 moles. Compound $\mathbf{5 9}$ was then hydrolyzed to $\mathbf{6 0}$, by reflux in solution of $\mathrm{HBr}$ in acetic acid for 17 hours in anhydrous environment, and $\mathbf{6 0}$ was then converted to $\mathbf{6 2}$.

Compounds 58 (Scheme 9), 64 and 69 (Scheme 10) are strongly fluorescent dyes with bright yellow shade as was evaluated on polyester fibers. Tricyano dyes $\mathbf{6 5}$ and 70 (Scheme 11) have deep colors compared to the monocyanate starting materials. Their structures showed some analogy to the tricyanoethylene category of dyestuffs, 
but when they were applied on polyester, they displayed poor color strength and good light fastness [44].

Compound 71 was synthesized by chlorination of l-benzamidoanthraquinone followed by acid hydrolysis. Reaction of $\mathbf{7 1}$ with 2-cyano$\mathrm{N}, \mathrm{N}$-di(piperidin-1-yl)acetamide in presence of phosphorous oxychloride, afforded 72 (Scheme 11) which was then subjected to condensation with amines under Ullmann reaction conditions to provide the corresponding 6-aminated derivatives 73 .
Magenta to violet colored azabenzanthrones were more bathochromic than other ringclosed derivatives, such as pyridanthrones and pyrimidanthrones. The ring-closure was found to reduce the dye uptake compared to the 1,4-disubstituted anthraquinones analogous. Light fastness was found to vary between moderate, for 6-alkylamino derivatives, to good, for 6-arylamino derivatives. Results indicated potential application of ring-closed azabenzanthrones as practical disperse dyestuffs [45].<smiles>[R]c1cc([R])c(N)cc1[R]</smiles>

54<smiles>[R2]c1cc([R])c(N=[N+]=[N-])cc1[R]</smiles>

$+50$<smiles>[R]c1cc([R2])c(N=Nc2c(N)ccc3nc(OC)cnc23)cc1[R]</smiles>

Scheme 8<smiles>Cc1nn(-c2ccccc2)c(Cl)c1C=O</smiles>

Scheme 9 


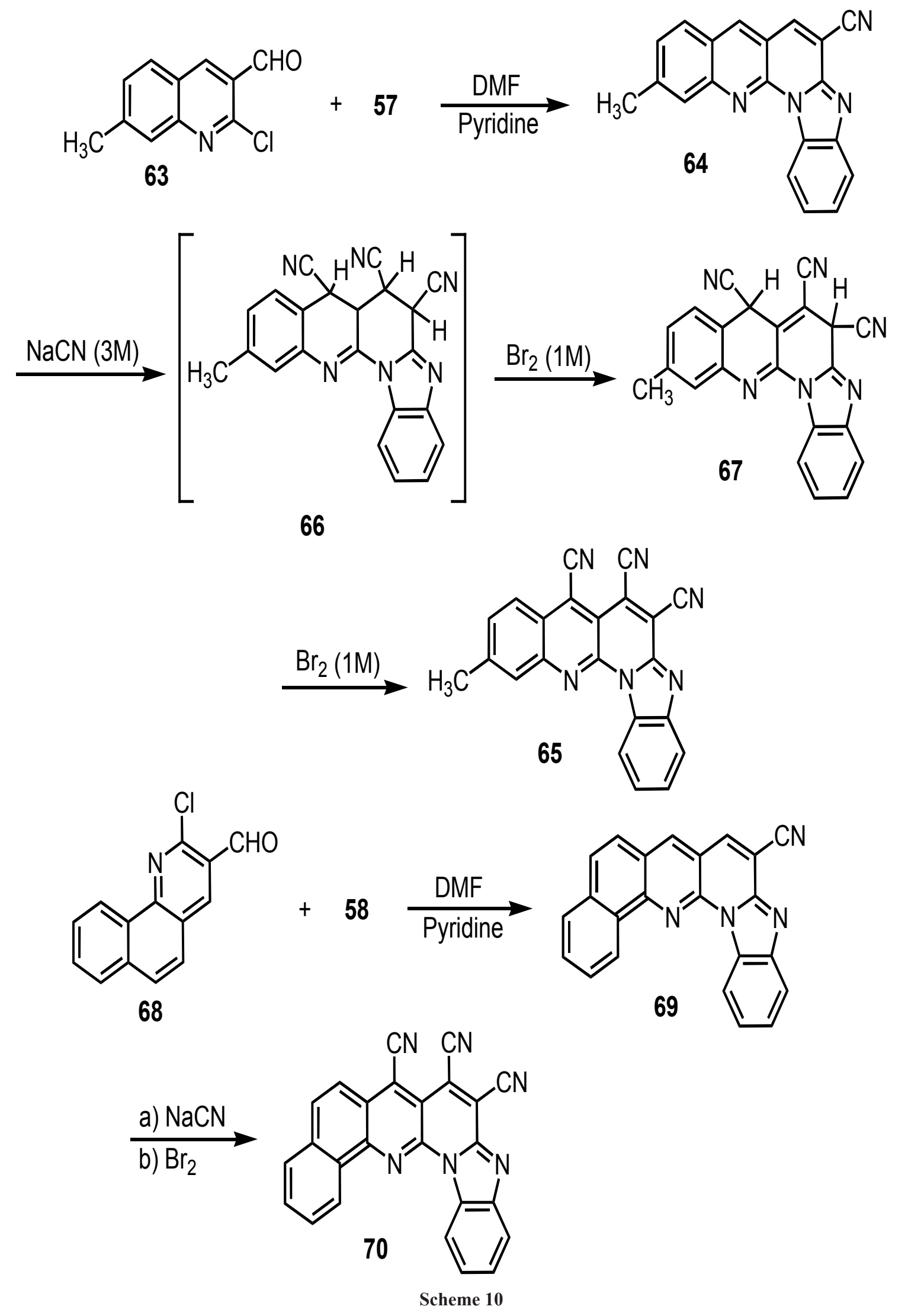

Egypt. J. Chem. 61, No.6 (2018) 
1-Aminoanthraquinone and 1, 5-diaminoanthraquinone were interacted with excess of acetone and butanone, which by process of self-condensation were converted into $\alpha, \beta-$ unsaturated ketones, at reflux for 12 hours and in presence of excess anhydrous aluminum chloride as a catalyst to give the corresponding dyes $\mathbf{7 4}$ and $\mathbf{7 5}$, respectively.

Also pyridinoanthraquinones have been synthesized by first preparing 'anthraquinonyl aminoacrylates' and subsequent cyclization in diphenyl ether at $200^{\circ} \mathrm{C}$ [46]. Dyes 74 and 75 afforded violet to bluish-violet shades and comparatively poor light and sublimation fastness on polyester garments [47] (Scheme 12).

Compound 78 was obtained via condensation of 77 with $\mathbf{7 6}$ in polyphosphoric acid. After stirring at $210^{\circ} \mathrm{C}$ for 6 hours, the mixture was poured into a mixture of water and ice and the $\mathrm{pH}$ was then adjusted at 5 . The diazonium salt of $\mathbf{7 8}$ [48-50] was then exposed to azo-coupling with 79 [51] to give 80 [52] (Scheme 12).

All attempts of azo-coupling using the diazonium salt from the ortho isomer of the amine $\mathbf{7 8}$ gave the imidazopyridine benzotriazine $\mathbf{8 1}$ [53] (Scheme 12).

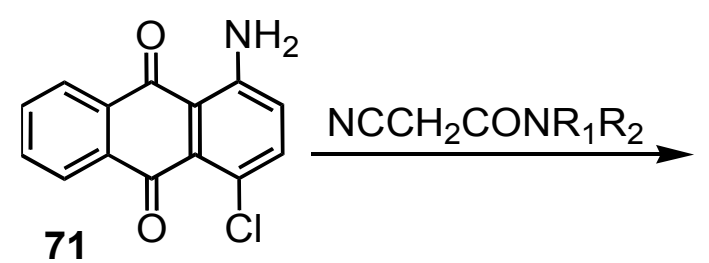

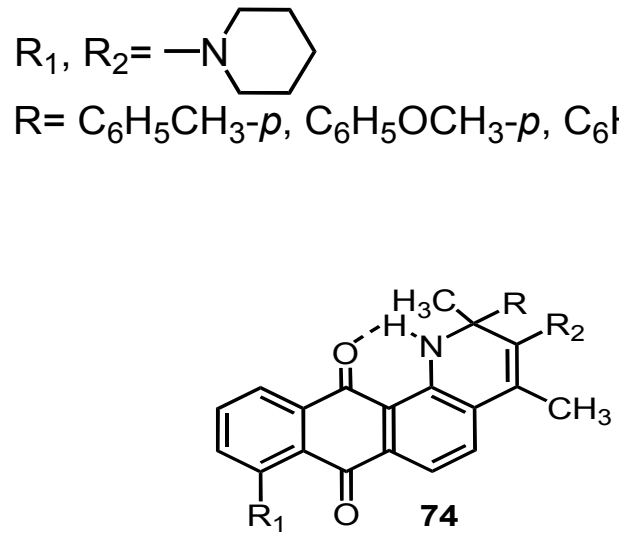

$\mathrm{R}=\mathrm{CH}_{3}, \mathrm{C}_{\dot{2}} \mathrm{H}_{5} ; \mathrm{R}_{1}=\stackrel{\mathrm{H}}{\mathbf{2}}, \mathrm{NH}_{2} ; \mathrm{R}_{2}=\mathrm{H}, \mathrm{CH}_{3}$<smiles>[R]C1=C(C)c2ccc3c(c2C(=O)c2ccc4c(c2N1)N(C)C([R])(C)C([R])=C4C)C(=O)c1ccc2c(c1NC3(C)C)C([R])C2</smiles>

$\mathrm{R}=\mathrm{CH}_{3}, \mathrm{C}_{2} \mathrm{H}_{5} ; \mathrm{R}_{1}=\mathrm{H}, \mathrm{CH}_{3}$<smiles>Nc1[X]cccc1N</smiles>

76<smiles>[R2]Nc1nc2ccc(Cl)c3c2c(c1C#N)-c1ccccc1C(=O)C3CCC</smiles><smiles>[R]Nc1ccc2nc(N[R2])c(C#N)c3c2c1C(=O)c1ccccc1-3</smiles>

Scheme 11

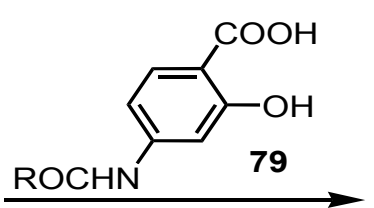<smiles></smiles>

Scheme 12 
Benzo(or pyrido)imidazoles are appropriate disperse dyes for the coloration of polyamide fibers. Exhaustion, leveling and color yield were satisfactory. Fastnesses to tetrachloroethylene, rubbing (dry and wet), and spotting with acetic acid was generally excellent. Light fastness was enhanced by the imidazole and pyrido rings, and para substitution. Fastness to washing was highest for dyes containing benzo ring, and meta substitution, while fastness to alkaline spotting was highest with meta substitution. Fastness to perspiration was excellent for the whole series with exception of few cases. Overall, dye $80(\mathrm{R}=$ $\mathrm{C}_{15} \mathrm{H}_{31} ; \mathrm{X}=\mathrm{N} ; \mathrm{Y}=\mathrm{NH}$, azoaryl at 4-position) had excellent properties. The present heterocyclic dyes show better colorfastness properties than their non-heterocyclic analogues with the same coupling moiety [51-53].

The sodium salt 82 was used as coupling component for preparing $\mathbf{8 3}$ which was then condensed with $\mathbf{8 4}$ via reflux for 5 hours in acetic acid to give $\mathbf{8 5}$ which was oxidized, using copper(II) acetate and dimethylformamide in a current of air, to afford 86 (Scheme 13).
The nitro substituent in $\mathbf{8 6}$ was subjected to reduction using a mixture of zinc and acetic acid, heating was continued for 3 hours at reflux, to provide the corresponding amino derivative which was acetylated by acetic anhydride, heating was continued for 3.5 hours at reflux, to give the acetamido derivative.

Disperse dyes displayed fluorescence maxima close to green, greenish-blue and blue regions. The yellow-colored dye $86\left(\mathrm{R}=\mathrm{NO}_{2}\right)$ dyed polyester fiber in lemon yellow shade with good colorfastness to light and sublimation, while the pale yellow-colored derivative $\mathbf{8 6}\left(\mathrm{R}=\mathrm{NHCOCH}_{3}\right)$ had moderate fluorescent activity on polyester. The derivative $86\left(\mathrm{R}=\mathrm{CH}_{3}\right)$ and $86\left(\mathrm{R}=o-\mathrm{CH}_{3}\right)$ dyed polyester fibers in yellowish-brown shade with moderate color strength and sublimation fastness [54] (Scheme 14). Compound 87 was condensed to afford the corresponding heterocyclic imidazopyridine [55] (Scheme 14). Coupling of diazonium salts of $\mathbf{8 8}$ and $\mathbf{8 9}$ was performed in glacial acetic acid at $18^{\circ} \mathrm{C}$. After 2 hours, the $\mathrm{pH}$ was adjusted at 4.5 to give 126. The dyes 91 were produced by reflux of the corresponding 90 with excess of iodomethane (Scheme 14).

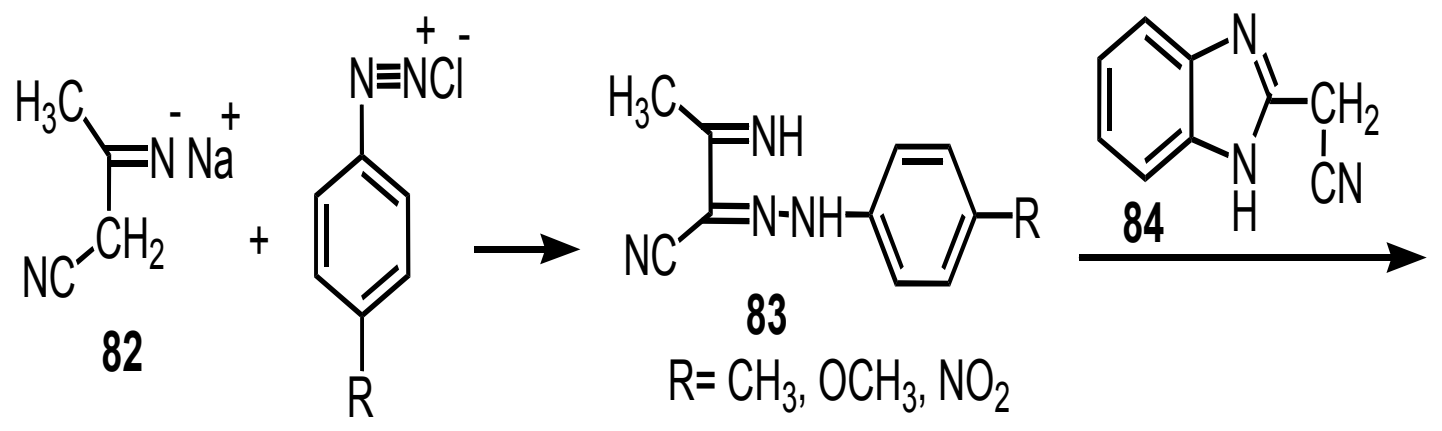<smiles>[R]c1ccc(N=Nc2c(C)c(C#N)c3nc4ccccc4n3c2N)cc1</smiles><smiles>[R]c1ccc(-n2nc3c(C)c(C#N)c4nc5ccccc5n4c3n2)cc1</smiles>

\section{$\mathrm{R}=\mathrm{CH}_{3}, \mathrm{OCH}_{3}, \mathrm{NO}_{2}, \mathrm{NH}_{2}, \mathrm{NHCOCH}_{3}$}




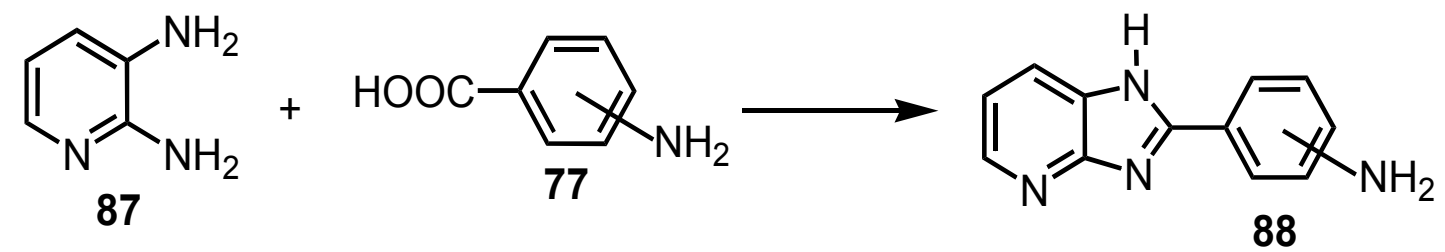<smiles>[Y4]CCN(CC[Y4])c1cccc(N=Nc2ccc(-c3nc4ncccc4[nH]3)cc2)c1[Y]</smiles><smiles>[Y4]CCN(CC[Y4])c1ccc(N=Nc2ccc(-c3nc4c(ccc[n+]4C)[nH]3)cc2)c([Y])c1</smiles>

Scheme 14

Disperse dyestuffs 90 were found to be appropriate for dyeing polyamide and polyester, affording satisfactory dye-bath exhaustion, leveling and color yield. Some dyeings displayed slight tendency to phototropic variations. dyes 91 $\left(\mathrm{X}_{1}=\mathrm{CH}_{3} ; \mathrm{X}_{2}=\mathrm{H} ; \mathrm{X}_{3}=\mathrm{H}\right.$ and $\mathrm{CN}$ ) (Scheme 14) are of especial interest because all derivatives showed excellent colorfastness to perchloroethylene and to acetic acid on both polyamide and polyester substrates, and to sodium carbonate, to dry and wet rubbing fastness on polyamide, to wash fastness (at 40 and $60^{\circ} \mathrm{C}$ ), and to acidic and alkaline perspiration on polyester. However, dyestuffs had low colorfastness to severe on polyamide, and poor rubbing fastness on polyester. Light fastness was generally moderate, being slightly better on polyamide. Cationic dyes dyed acrylic fibers with acceptable exhaustion of dye liquors, color yield and leveling without the need for a retarder. Characteristics of cationic dyestuffs were of good values, although lower than the corresponding derivatives of the unquaternized disperse dyes [55].<smiles>[R]C1CCCCC1C=O</smiles>

92
$\mathrm{H}$<smiles>N#CCc1nc2ccccc2[nH]1</smiles>

4

94<smiles></smiles>

93

Scheme 15 
<smiles>CCN(CC)c1ccc(C(C)c2nc3ccccc3[nH]2)c(OC)c1</smiles>

Scheme 16

Reaction of 92 with benzimidazole-2acetonitrile followed by cyclization of the resultant styryls 93 to afford 94 (Scheme 15) which were reported to be fluorescent brighteners for polyesters [3]. 4-Diethylaminosalicylaldehyde was reacted with dimethylsulfate in alkali employing the standard methylation process at $40-50^{\circ} \mathrm{C}$ to yield 95 . The reaction of 95 with benzimidazole-2-acetonitrile by reflux in ethanol for 1 hour and in presence of piperidine, gave the intermediate 96, which was cyclized at reflux for 4-5 hours in $o$-dichlorobenzene and in presence of piperidine acetate as a catalyst, to give 97. Dye 97 displayed intense fluorescence and afforded greenish-yellow fluorescent shade on polyester. Reduction of 97 using Raney Ni-formic acid method [56] at reflux, gave the formyl derivative 98 (Scheme 16) which was reacted with 99 , in ethanol for 2 hours at reflux, to yield the respective styryl dyes 100 (Scheme 17).

Oxidative cyanation of 97 using a mixture of sodium cyanide and dimethylformamide together with bromine, gave deep red dicyano derivative 101. However, 101 did not behave effectively as a dye on polyester fibers, which could be attributed to its instability under high-temperature dyeing conditions. Though styryl derivatives $\mathbf{1 0 0}$ displayed good fluorescence performance and afforded attractive orange to pink-red shades on polyester, their colorfastness to light and sublimation were generally poor [57].
97

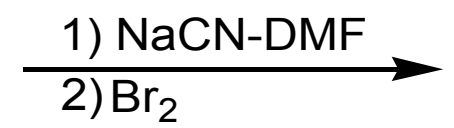<smiles>CCNc1ccc2c(C#N)c(C#N)c3nc4ccccc4n3c2c1</smiles>

$\mathrm{X}, \mathrm{Y}=\mathrm{CN}, \mathrm{CO}_{2} \mathrm{Et}$,<smiles>Cc1ccc([N+](=O)[O-])cc1</smiles>

99<smiles>[Y]C([Y])=Cc1cc2ccc(NCC)cc2n2c1nc1ccccc12</smiles>

Scheme 17<smiles>Cc1nc2ccccc2[nH]1</smiles>

Egypt. J. Chem. 61, No.6 (2018) 
The disperse dye $\mathbf{1 0 2}$ was prepared by diazotization of 3 or 4-aminophenyl-imidazolopyridines) and concentrated hydrochloric acid at $10-12^{\circ} \mathrm{C}$ to afford the corresponding diazonium salt which was then added to a solution of $N, N$ diethylaniline in acetic acid at $10-12^{\circ} \mathrm{C}$ with stirring. Dye 103 was prepared by refluxing the corresponding disperses dye $\mathbf{1 0 2}$ with large excess of iodomethane dissolved in tert-butyl alcohol for 20 hours (Scheme 18).

Disperse dye 102 showed great versatility towards polyamide, polyester, cellulose acetate fibers, and, after quaternization, cationic dye
103 was applied successfully on acrylic fibers. Satisfactory color yield, compared to commercial dyestuffs applied under the same conditions, was produced at $0.25-1 \%$ depth. Excellent leveling and exhaustion properties of dye liquors were also accomplished. Cationic dye $\mathbf{1 0 3}$ afforded excellent uniformity of coloration on acrylic fibers without using a retarding agent. Excellent behavior was monitored in colorfastness to wash at $40^{\circ} \mathrm{C}$, perspiration, sodium carbonate and acetic acid. Dyeing data on polyester fibers were excellent with the exception of light fastness, which was higher on polyamide and cellulose acetate [58].

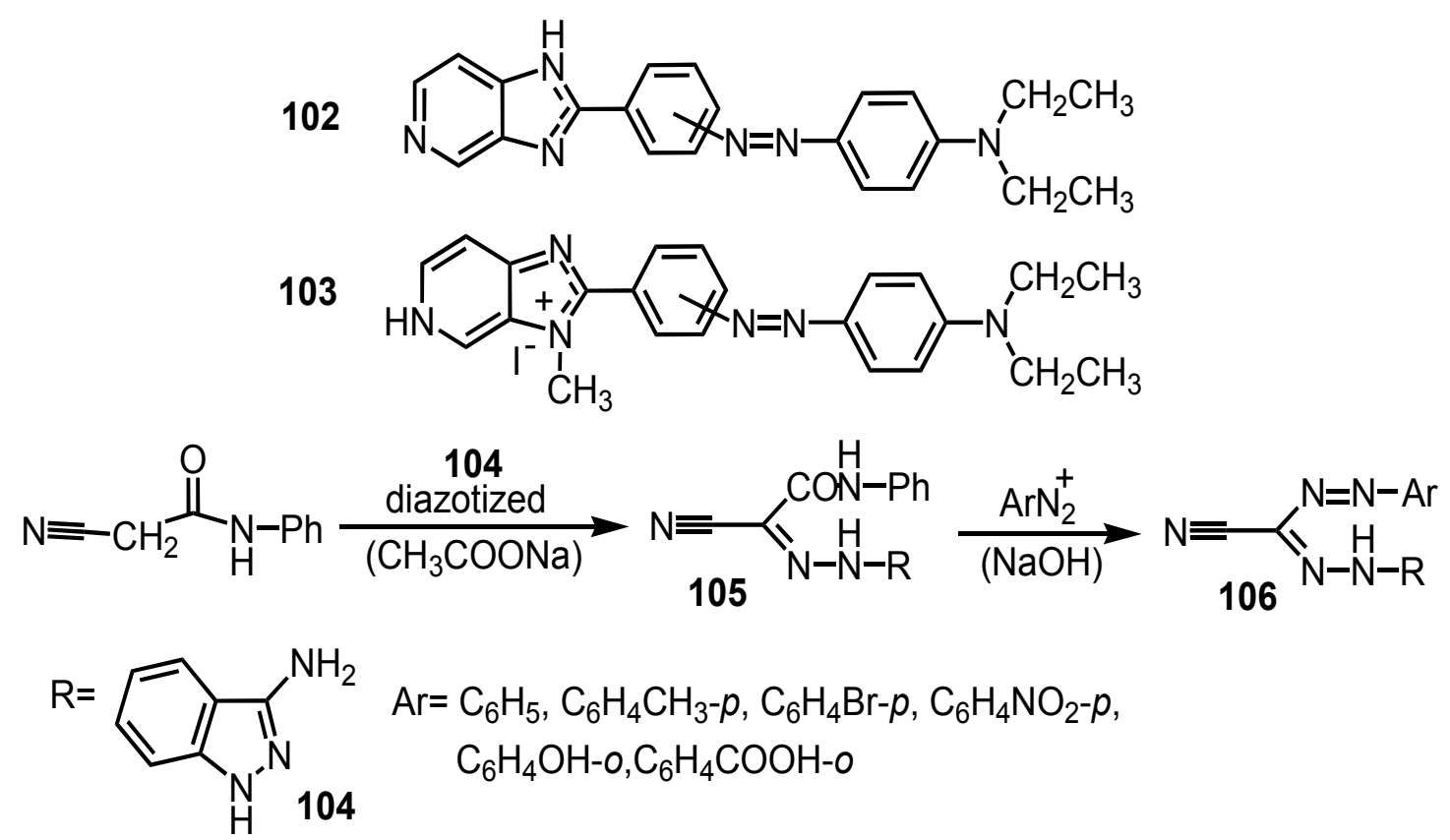

Scheme 18

Compound 104 was diazotized and coupled with 2-cyano- $N$-phenylacetamide in a sodium acetate buffered solution to form 105 (Scheme 18). Reaction between the arene diazonium ions and 105, in presence of sodium hydroxide, produced the corresponding asymmetrical 3-cyanoformazan derivatives $\mathbf{1 0 6}$.

Compounds 105 and 106 (Scheme 18) were evaluated as direct, acid and basic dyes. Coloration properties on wool, nylon and cellulosic fibers were good. All dyeings had very good colorfastness to light, although colorfastness to wash was moderate [59].

Compound 107 was reacted with the activemethylene keto compounds $\mathbf{1 0 8}$ in refluxing ethanol containing sodium ethoxide for 6 hours. Reaction of 108 gave 109 together with 110
(Scheme 19). When 107 reacted with $108\left(\mathrm{R}_{1}=\mathrm{OH}\right)$ in refluxing ethanol containing sodium ethoxide, the compound $109\left(\mathrm{R}_{1}=\mathrm{OH}\right)$ was obtained. The reaction of 107 with 111 in similar manner gave 112 (Scheme 19). Condensation of the ethylester group in $\mathbf{1 0 9}$ or carboxylic acid group in $\mathbf{1 1 0}$ with $o$-phenylenediamine via refluxing in ethane-1,2diol for 5 hours, produced 113. 5-Cyano group in $\mathbf{1 1 2}$ was similarly converted into $\mathbf{1 1 5}$ which was also obtained directly by reaction of $\mathbf{1 0 7}$ with 2-cy anomethylbenzimidazole(Scheme 20).

5-Hetarylpyrazolo[3, 4-b]pyrazines 113115 were applied to polyester as disperse dyestuffs affording fluorescent yellow, orange and yellowish-brown shades with good uptake, moderate light fastness and good sublimation fastness [60] (Scheme 19). 


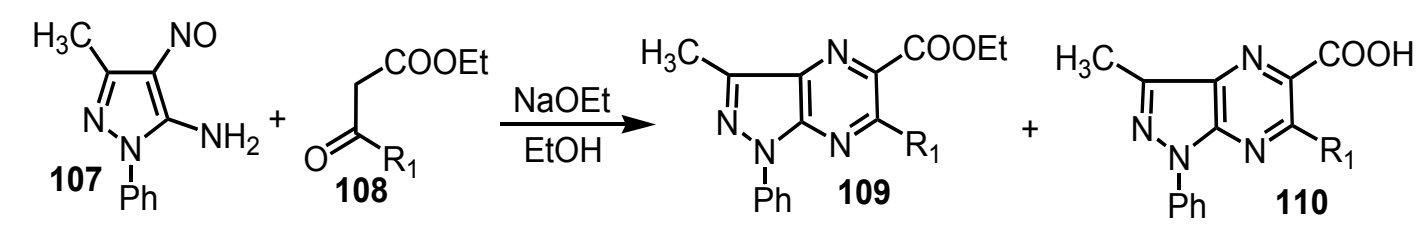

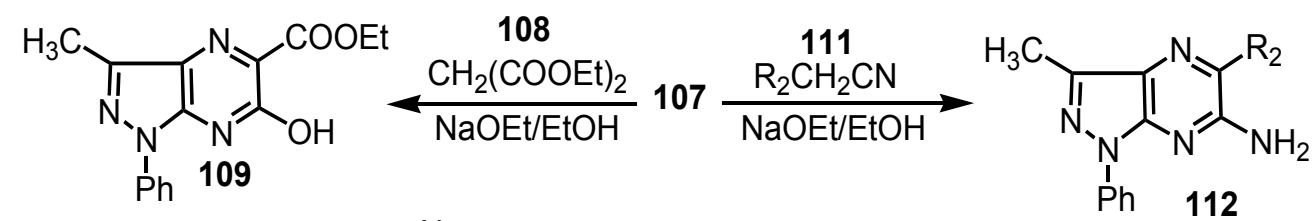<smiles>[R]c1nc2c(nc1-c1nc3ccccc3[nH]1)c(C)nn2-c1ccccc1</smiles>

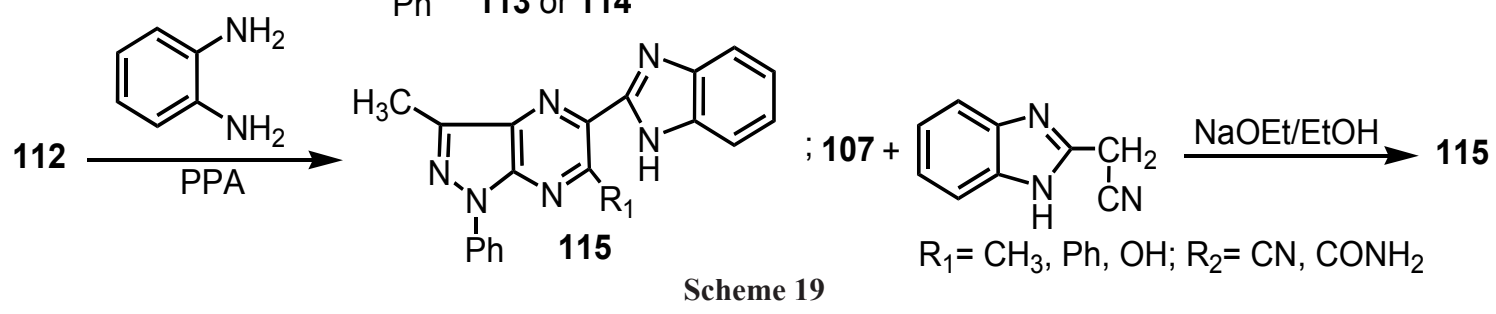<smiles>CC(=O)Nc1ccccc1C(=O)O</smiles><smiles>Cc1ccc(C=Cc2nc3ccccc3c(=O)[nH]2)cc1</smiles>

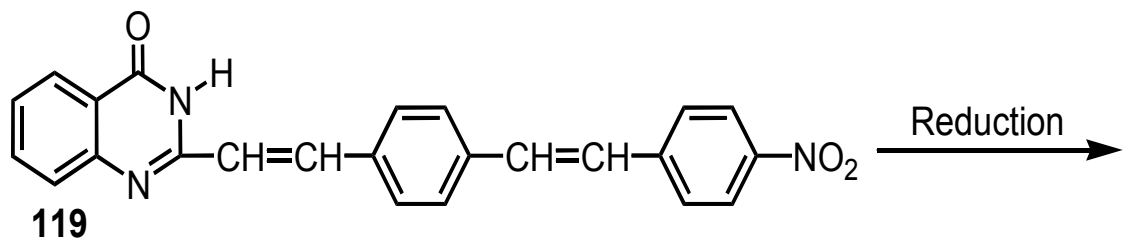<smiles>Nc1ccc(C=Cc2ccc(C=Cc3nc4ccccc4c(=O)[nH]3)cc2)cc1</smiles>
120

121<smiles>[R]N=Nc1ccc(C=Cc2ccc(C=Cc3nc4ccccc4c(=O)[nH]3)cc2)cc1</smiles>

Scheme 20 
Ring closure of $\mathrm{N}$-acetylanthranilic acid by refluxing with acetic anhydride for 40 minutes, afforded 116, which was converted into 117 by reaction with ammonia. Condensation of the methyl group in $\mathbf{1 1 7}$ with 4-methylbenzaldehyde via refluxing in acetic anhydride for 2 hours gave styryl derivative 118, and hence, by further condensation with 4-nitrobenzaldehyde, bisstyryl 119 was produced. Reduction of 119 with a solution of sodium sulfide in water, reflux for 2 hours, gave amino derivative $\mathbf{1 2 0}$ which was used as diazo component in synthesis of dyes $\mathbf{1 2 1}$ (Scheme 20)

$\mathrm{R}(\mathbf{1 2 1})=\mathrm{H}$-acid, J-acid, $\gamma$-acid, G-acid, R-salt, $N$-Methyl-J-acid, $N$-Phenyl-J-acid, Schaffer's acid, 1-(4'-Sulfophenyl)-3-methyl-5-pyrazolone, Peri-acid, 2-Naphthylamine-3,6,8-trisulfonic acid, 1-4'-Sulfophenyl-5-pyrazolone, Naphthol derivatives, 1-Phenyl-3-methyl-5-pyrazolone, 1-(4'-Sulfophenyl)-3-carboxy-5-pyrazolone, 1-(2,5'-Dichloro-4' -sulfophenyl)-3-methyl-5pyrazolone.

Dyes 121 gave satisfactory dyeing on silk, viscose or polyester as acid, direct or disperse dyestuffs and varied in shade from yellow to violet. Colorfastness to wash on viscose and silk varied from moderate to good, while light fastness was in general better on silk and polyester [61].
Compound 122a was produced by nitration of carbazole in acetic acid [62]. 3, 6-Dinitrocarbazole was subjected to reduction by hydrazine hydrate in presence of Raney nickel in $N, N$-dimethylformamide [62]. Compound $\mathbf{1 2 2 b}$ was obtained by Porai-Koshits and Salamon by nitration of benzidine sulfate, reduction and finally cyclization. Compound 122c was obtained by nitration of fluorenone, transformation of 2,7-dinitrofluorenone into oxime, Beckmann rearrangement to 3,8-dinitrophenanthridone, and finally reduction by iron. Compounds $\mathbf{1 2 2}$ were diazotized followed by dropwise addition to $\mathrm{H}$ - or $\mathrm{J}$-acid in $\mathrm{Na}_{2} \mathrm{CO}_{3}$ solution to give $\mathbf{1 2 3}$ and 124, respectively (Scheme 21) and (Table 2).

3, 8-Diaminophenanthridone derivatives of benzidine based dyes, containing additionally cyclic secondary amine or amide group, displayed favorable properties on cellulosic fibers with respect to color and affinity [62].

TABLE 2.

\begin{tabular}{ccc}
\hline Dye & X & Y \\
\hline 123a & NH & - \\
123b & - & NH \\
$123 c$ & - & CONH \\
124 & - & CONH \\
\hline 6_-6indicates direct link between phenyl rings.
\end{tabular}

"_“indicates direct link between phenyl rings.<smiles>[Y]c1cc(N=Nc2c(S(=O)(=O)O)cc3cc(S(=O)(=O)O)cc(N)c3c2O)ccc1[Y]c1cc(N)ccc1[X]</smiles><smiles>[X]c1cc(N=Nc2c(S(=O)(=O)O)cc3cc(N)ccc3c2O)ccc1[Y]c1cc(N=Nc2c(S(=O)(=O)O)cc3cc(N)ccc3c2O)ccc1[Y4]</smiles>

Scheme 21

Egypt. J. Chem. 61, No.6 (2018) 
Vilsmeier reaction of 6-methoxy-1-tetralone 125 afforded 126 (Scheme 22) which were reacted with benzimidazo-2-acetonitrile via reflux for 4 hours in dimethylformamide and in presence of pyridine to give 127. Dye $\mathbf{1 2 7}$ exhibits greenishyellow fluorescence and brilliant-yellow shade on polyester. Moeckli [43] described the cyanation at the 4-position of coumarins containing electronwithdrawing substituent at the 3-position. Dye 127 is structurally related to 3 -cyano coumarins and was thus anticipated to undergo nucleophilic attack by cyanide ion. Gokhale and Seshadri [44] described the cyanation of similar benzimidazo quinolines. Cyanation of $\mathbf{1 2 7}$ was performed via treatment of its solution in dimethylformamide with sodium cyanide and then with bromine at low temperature. Dicyano derivative 129 (Scheme 23) was isolated; it exhibited greenish-yellow fluorescence and was dyed on polyester in bright yellow-orange shade. Oxidation of $\mathbf{1 2 7}$ and $\mathbf{1 2 9}$ to the corresponding naphthalene derivatives $\mathbf{1 2 8}$ (Scheme 23) could not be performed under the usual reaction circumstances. Reaction of $\mathbf{1 2 5}$ with 2-aminobenzimidazole under alkaline conditions afforded 126. Compound $\mathbf{1 2 5}$ was refluxed for 3 hours with cyanoacetamide or cyanoacetanilide in dimethylformamide and in presence of pyridine to yield benzo-[h]-quinolines 130.

Fused indazoles 131 (Scheme 23) was prepared by refluxing $\mathbf{1 2 5}$ with arylhydrazines in dimethylformamide or ethyl alcohol and in presence of acetic acid as a catalyst for 3 hours.

Dyes 127 and 129 gave dyeings with good light fastness, high uptake, and sublimation fastness. Dye 131 (Ar= 2,4-dinitrophenyl) had moderate dyeing properties. Other compounds afforded dyeings with poor colorfastness to light and sublimation [63].

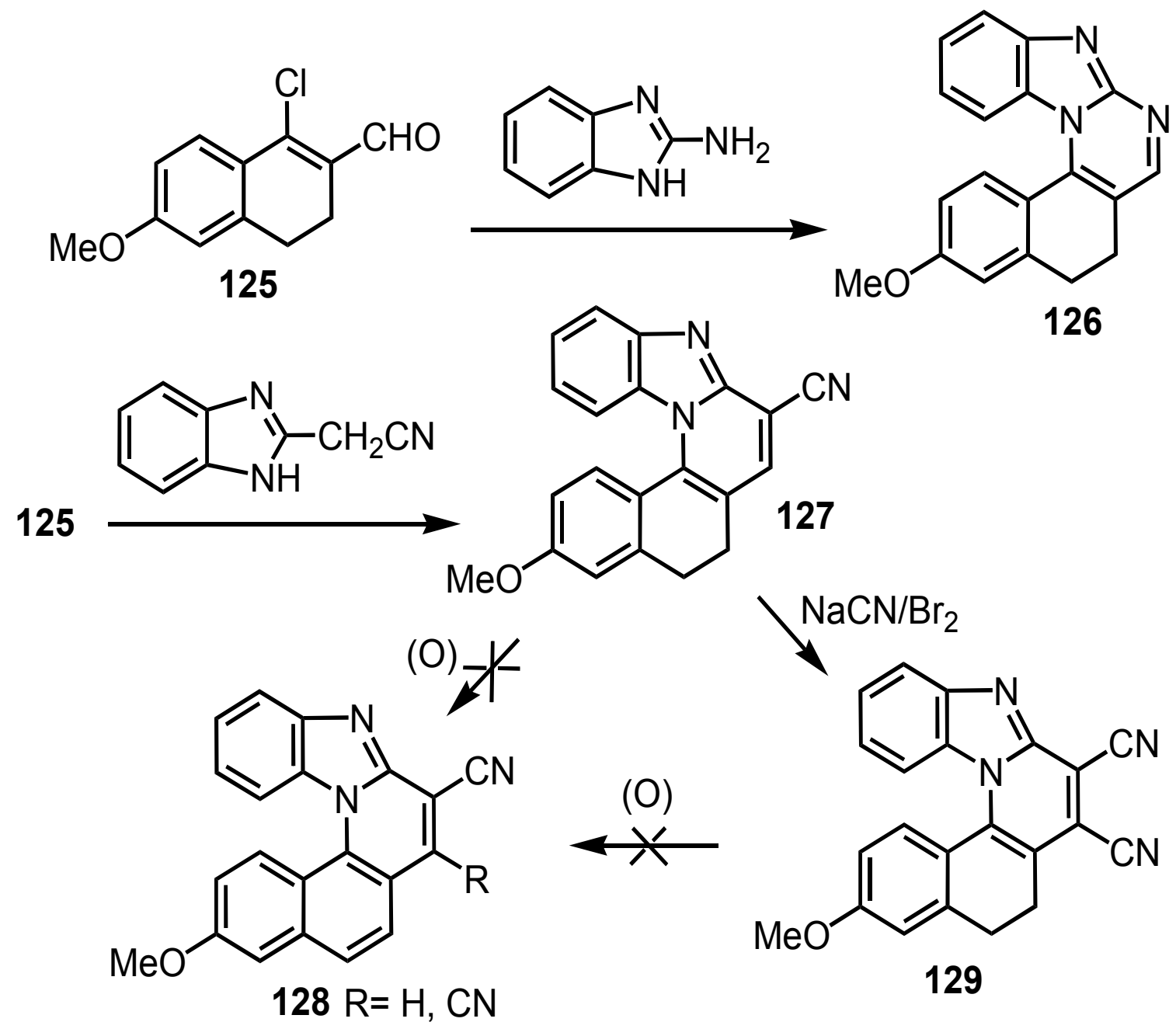

Scheme 22

Egypt. J. Chem. 61, No.6 (2018) 


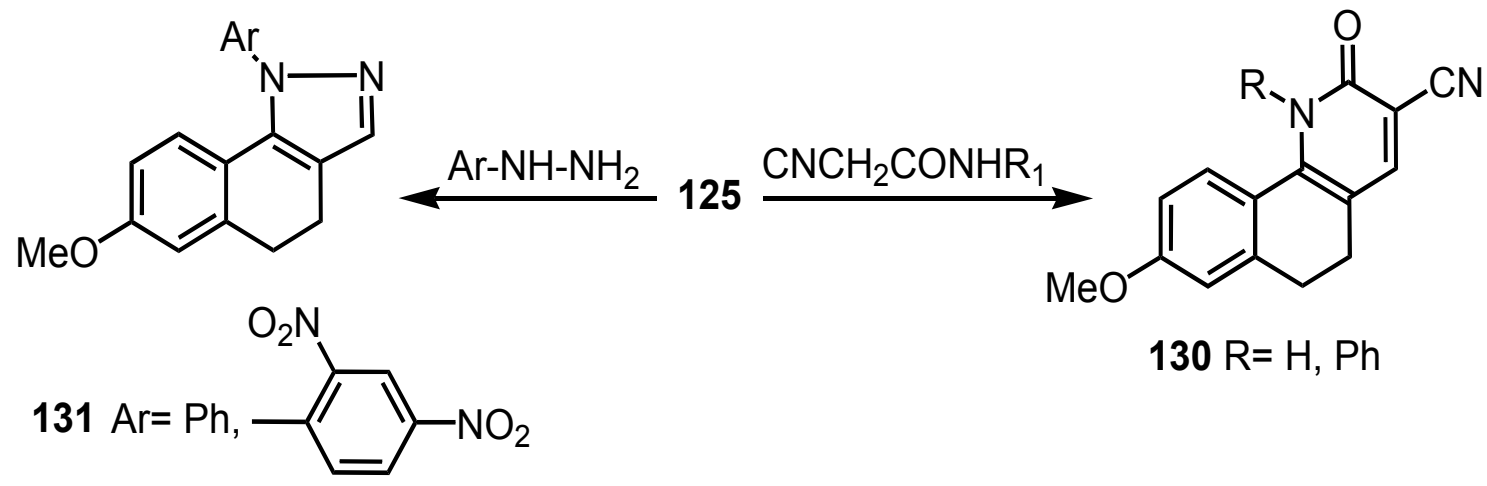

Scheme 23

Disperse dyes 132a-b (Fig. 2) and (Table 3) were obtained by diazotization of the corresponding amines ( $p$-aminophenylimidazolo[4,5-c]pyridines) followed by coupling with $N, N$-diethylaniline in acetic acid at $\mathrm{pH} 4.5$. Cationic dyes 132c-d (Fig. 2) and (Table 3) was obtained by refluxing $132 \mathbf{a}-\mathbf{b}$ with excess of methyl iodide in tert-butyl alcohol for 20 hours.

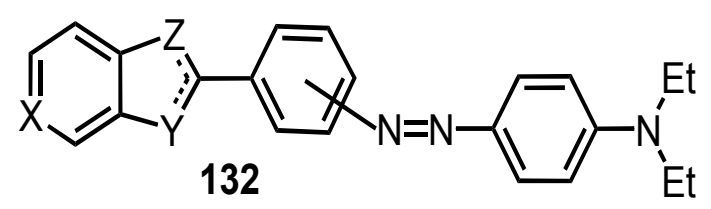

Fig. 2. Chemical structure dyes 132.

TABLE 3. dyes 132 derivatives

\begin{tabular}{cccc}
\hline Dye no. & $\mathbf{X}$ & $\mathbf{Y}$ & $\mathbf{Z}$ \\
\hline 132a & $\mathrm{N}$ & $\mathrm{N}$ & $\mathrm{NCH}_{3}$ \\
132b & $\mathrm{N}$ & $\mathrm{NCH}_{3}$ & $\mathrm{~N}$ \\
132c & ${ }^{+} \mathrm{NCH}_{3} \mathrm{I}^{-}$ & $\mathrm{N}$ & $\mathrm{NCH}_{3}$ \\
132d & ${ }^{+} \mathrm{NCH}_{3} \mathrm{I}^{-}$ & $\mathrm{NCH}_{3}$ & $\mathrm{~N}$ \\
\hline
\end{tabular}

Washing, rubbing and perspiration fastness properties of dyes was evaluated between very good to excellent on polyester, polyamide and cellulose acetate fibers with the disperse dyes. Similarly, acrylic fibers were dyed with the cationic dyes without use of retarding agent to introduce very good to excellent fastness properties against washing, rubbing and perspiration. Excellent exhaustion of dye liquors, leveling and color yield were produced at $0.25-1 \%$ depths. The light fastness generally displayed low to medium values, with exception of dyeings on cellulose acetate, which displayed, in some cases, very good light fastness [64].
Compound $133 \mathrm{~h}$ was produced by fusion of $o$-phenylenediamine with urea [65], followed by nitration by a mixture of nitric acid and sulfuric acid, and then reduction by iron [3]. Compound $\mathbf{1 3 4 h}$ was produced by similar approach, in the first stage $o$-phenylenediamine being fused with oxalic acid [66]. Compound $\mathbf{1 3 5 h}$ was produced by nitration of phthalimide followed by reduction of the nitro derivative using tin(II) chloride [67]. Compound 136h was obtained by heating 4-aminophthalimide with boiling aqueous hydrazine [68]. Amines 133136h (Scheme 24) were grinded with hydrochloric acid and then dissolved in water followed by diazotization at $0-5^{\circ} \mathrm{C}$ with $\mathrm{NaNO}_{2}$ solution. The produced diazonium salt was added to solution of J-acid or its $N$-benzoyl or $N$-phenyl derivative in an aqueous solution of sodium hydroxide to produce monoazo dyes. Diazonium salt, prepared above, was added to solution of sodium salt of Cleves- 6 acid or to suspension of $p$-cresidine in water at $0-5^{\circ} \mathrm{C}$, while $\mathrm{pH}$ was maintained at 6-7. Separated monoazo precipitate was stirred with water and hydrochloric acid and diazotized by the addition of sodium nitrite aqueous solution to produce disazo dyes. In case of preparation of trisazo dyestuffs, operation of diazotization and azo-coupling with Cleves-6 acid was repeated. Similar to the method used for synthesis of monoazo dyes, a suspension of the diazonium salt was produced from the monoazo or disazo compound followed by azocoupling with J-acid (Fig. 3).

Direct dyes containing cyclic imide moiety showed significant dye affinity to cellulose fibers, whilst the degree of exhaustion was low for analogous monoazo dyes lacking such imido moiety. The light fastness was higher for dyes with more extended system and also in case of dyestuffs in which amino substituent was acylated or arylated. Fastness to washing and rubbing were similar for analogous 'imide' and 'phenyl' dyes [69]. 
<smiles>[X]c1ccc2[nH]c(=O)c(=O)[nH]c2c1</smiles><smiles>[X]c1ccc2c(=O)[nH][nH]c(=O)c2c1</smiles><smiles>[X]c1ccc2c(c1)C(=O)NC2=O</smiles>

Scheme 24

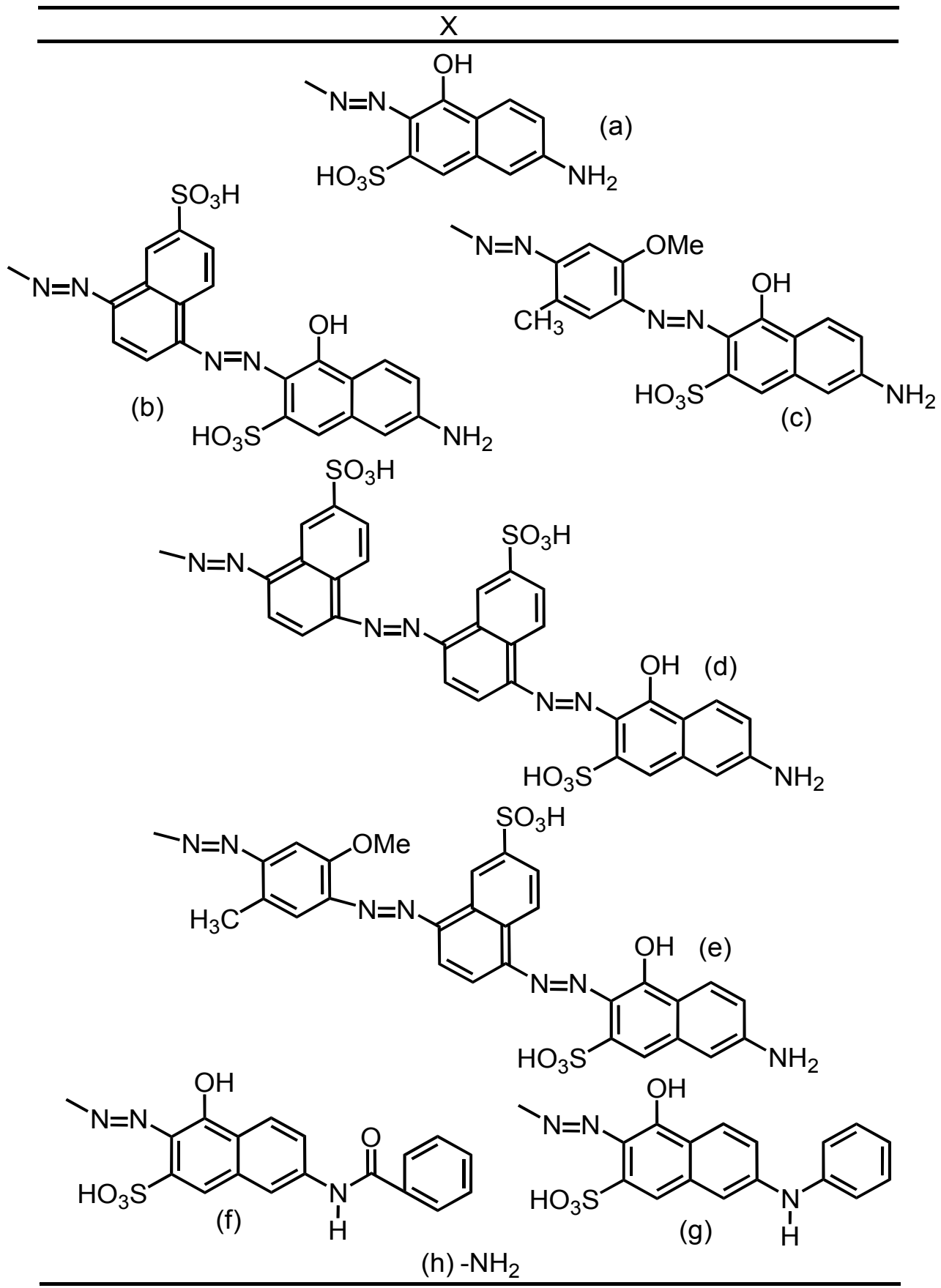

Fig. 3.J-acid and its $N$-benzoyl or $N$-phenyl derivative.

Egypt. J. Chem. 61, No.6 (2018) 
Compound 137 [70] was reacted with allylamine in boiling methanol for 4 hours to afford 138 which was then refluxed for 4 hours in ethanol with $(\mathrm{AH})$, and in presence of triethylamine to remove $\mathrm{HBr}$ from the reaction system leading to formation of dyes 139a-b. Mixture of 4-amino-1, 8-naphthalic anhydride $[70,71]$ and allylamine was refluxed in methanol for 3-4 hours to give dye 139c (Scheme 25).

Dyes possess strong yellow-orange fluorescence, as the aminonaphthalimides showed good coloration properties on synthetic fibers
[34]. Dyes 139a-c was found to have the same photostability. Absorption ability of dyes follows the order: $\mathbf{c}>\mathbf{b}>\mathbf{a}$ [72].

Disperse dyes 146a-p were prepared by coupling 144 with a variety of mono and di- $\mathrm{N}$ substituted derivatives of aniline R, while 140 [73, 74] and 142 [3] were prepared as title compounds (Scheme 26).

Dye 144 was prepared by condensation of 140 with 142 followed by reduction with $\mathrm{Fe} / \mathrm{HCl}$ in methanol (Scheme 27).<smiles>C=CCC(C)N</smiles><smiles>C=CC1CC1CC1CCCCC1</smiles><smiles>CCC(C)C</smiles><smiles>Nc1ccc2c3c(cccc13)C(=O)OC2=O</smiles><smiles>C=CCN</smiles><smiles>C=CCN1C(=O)c2cccc3c([As])ccc(c23)C1=O</smiles>$$
\mathrm{NH}_{2}
$$

Scheme 25<smiles>CC(=O)Nc1ccc(N(C)C(C)=O)cc1C(=O)O[Mg]</smiles>

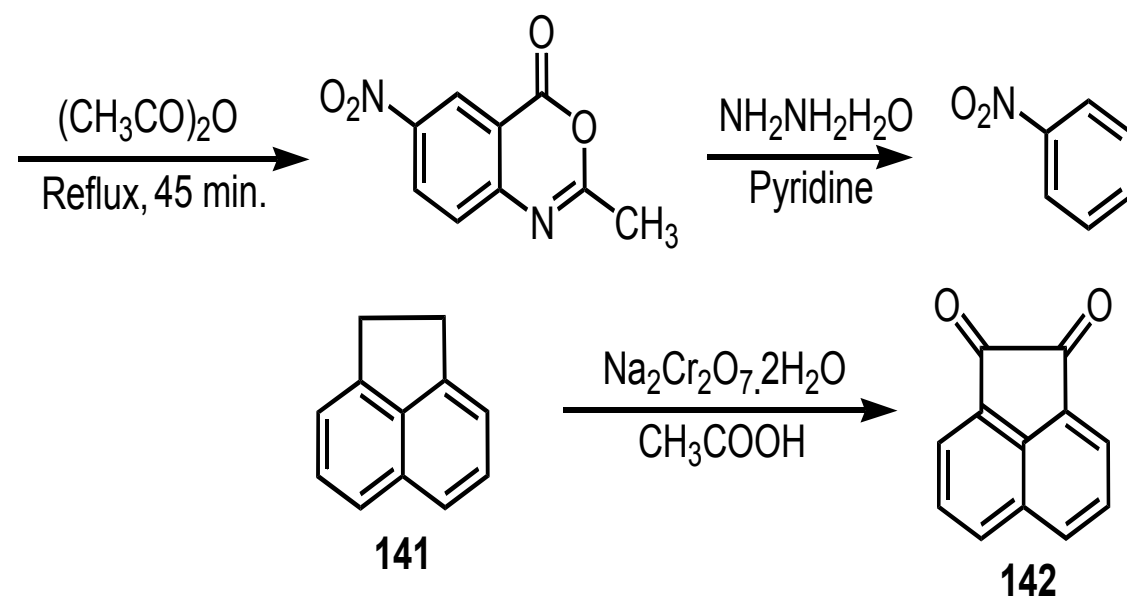

Scheme 26 


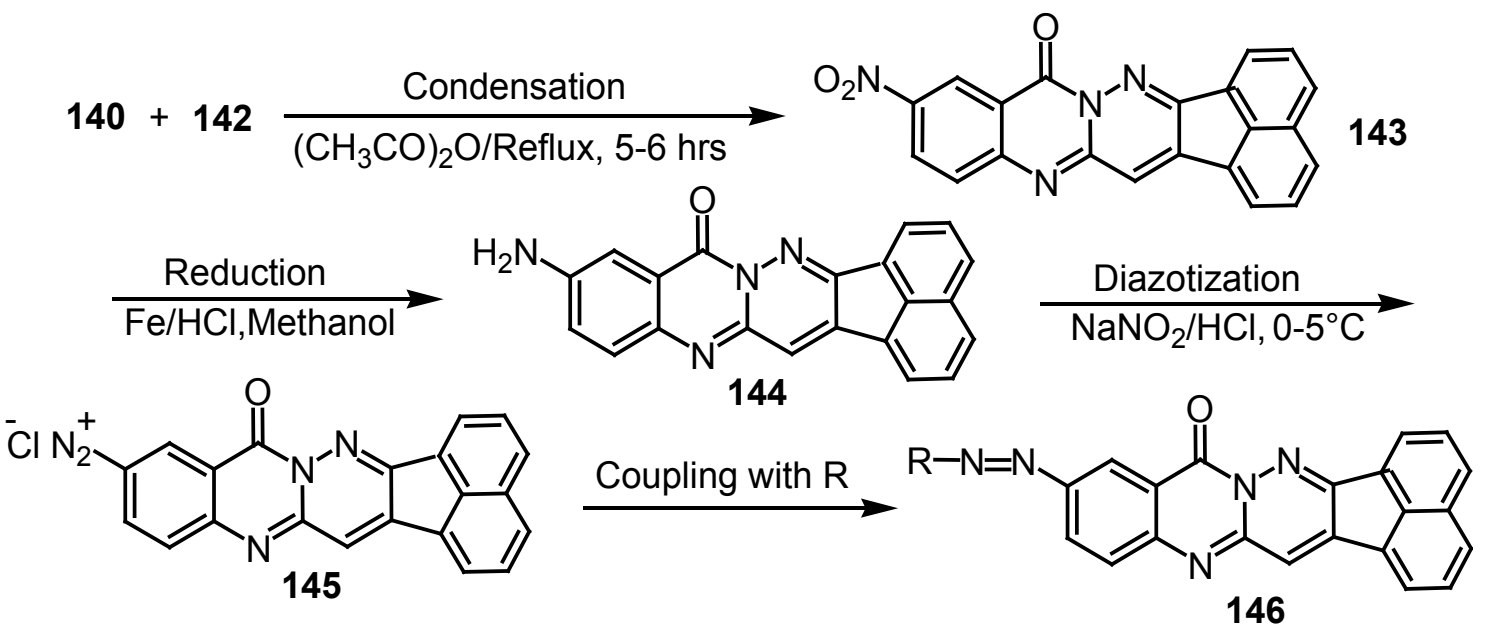

Scheme 27

TABLE 4. Derivatives of dye 146

\section{R (146)}

$\mathrm{a}=\mathrm{N}, \mathrm{N}$-bis(2-hydroxyethyl)aniline; $\mathrm{b}=\mathrm{N}, \mathrm{N}$-bis(2-hydroxyethyl)-m-aminoacetanilide;

$\mathrm{c}=\mathrm{N}, \mathrm{N}$-(diethyl)-m-aminoacetanilide; $\mathrm{d}=\mathrm{N}, \mathrm{N}$-(diethyl)-m-aminopropionate;

$\mathrm{e}=\mathrm{N}, \mathrm{N}$-bis(2-hydroxyethyl)-m-toluidine; $\mathrm{f}=\mathrm{N}$-methyl-N-monohydroxyethyl aniline;

$\mathrm{g}=\mathrm{N}$-mono-N-hydroxyethyl aniline; $\mathrm{h}=\mathrm{N}$-mono-N-hydroxyethyl-m-toluidine;

$\mathrm{i}=\mathrm{N}, \mathrm{N}$-bis(2-hydroxyethyl)-m-chloroaniline; $\mathrm{j}=\mathrm{N}$-ethyl-N-(2-hydroxyethyl) aniline;

$\mathrm{k}=\mathrm{N}, \quad \mathrm{N}$-bis(acetoxyethyl)-m-chloroaniline, $\mathrm{l}=\mathrm{N}, \quad \mathrm{N}$-bis(acetoxyethyl) aniline;

$\mathrm{m}=\mathrm{N}, \mathrm{N}$-bis(2-cyanoethyl) aniline; $\mathrm{n}=\mathrm{N}-(2$-cyanoethyl)-N-(2-hydroxyethyl) aniline;

$\mathrm{o}=\mathrm{N}$-methyl-N-cyanoethyl aniline; $\mathrm{p}=\mathrm{N}$-ethyl-N-cyanoethyl aniline.

Dyestuffs afforded mostly pink, yellow and brown shades on polyester and nylon 66 fibers possessing very good to excellent colorfastness to wash, sublimation, perspiration and rubbing. The exhaustion properties on different fibers were found to be reasonably good. Colorfastness to light ranged from fairly good to good for all disperse dyestuffs for both polyester and nylon 66 fibers except dyes 146a,c,f,g which were fair to fairly good [75] (Scheme 27) and (Table 4).

Compound 148 was produced by condensing 4-chloro-phthalic anhydride and 4-nitro-orthophenylenediamine in presence of acetic anhydride, and then reduction of 147 with $\mathrm{Fe} / \mathrm{HCl}$. Diazotization of 148 and azo-coupling with a variety of monoand di- $N$-substituted anilines produced disperse dyes 149a-o (Scheme 28) and (Table 5).
Dyes gave generally orange, red and brown hues on nylon 66 and polyester fibers that possess very good to excellent colorfastness to wash. Dyestuffs displayed higher exhaustion on nylon than polyester. Except for the dyes 149a, d, j, m; the colorfastness to light was good to very good on nylon 66, and except for $\mathbf{1 4 9 b}$, e, 1 , it was good to very good on polyester. Colorfastness to rubbing was good to excellent on both fabrics, while perspiration and sublimation fastness were excellent [76].

Soluble polycyclic derivatives of imidazoles and imides-based dyes $\mathbf{1 5 0}$ and $\mathbf{1 5 1}$ containing sulfonic group, which were prepared by direct sulfonation [77, 78] (Scheme 29).

Dyes were characterized by high fastnesses to washing, abrasion and light. Addition of 
sulfonic groups allowed them to be used as direct dyes. Color intensity of dyeings on cotton fibers depended mainly on fact whether dye is imide or imidazole derivative, as imidazoles showed higher substantivity [79].<smiles>Nc1ccc([N+](=O)[O-])cc1N</smiles><smiles>O=C1OC(=O)c2cc(Cl)ccc21</smiles>

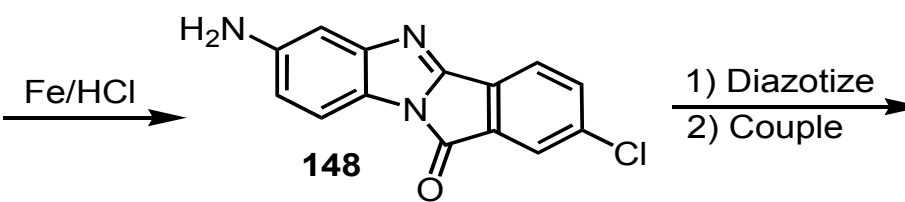

Scheme 28
Diazotization of 3-amino-1H-pyrazolo[3, 4-b]pyridine and azo-coupling with $\mathrm{R}_{1} \mathrm{H}$, gave dyestuffs 152. Methylation of $\mathbf{1 5 2}$ with $\left(\mathrm{CH}_{3}\right)_{2} \mathrm{SO}_{4}$ gave 153. Dyeings of 152 and 153 on polyester introduced good fastness to washing, rubbing, acid, perspiration and light.<smiles>CC(C)C</smiles><smiles>[R]N=Nc1ccc2c(c1)nc1n2C(=O)c2cc(Cl)ccc2-1</smiles>

TABLE 5. Derivatives of dye 149.

R (149)

$\mathrm{a}=N, N$-Bis(2-hydroxyethyl)aniline; $\mathbf{b}=m$-Acetamido- $N, N$-bis(2-hydroxy ethyl)aniline;

$\mathrm{c}=m$-Acetamido- $N, N$-bis (diethyl) aniline; $\mathrm{d}=N, N$-Bis(2-hydroxy ethyl)- $m$-toluidine;

$\mathrm{e}=N, N$-Bis(2-cyano ethyl)aniline; $\mathrm{f}=N, N$-Bis(2-hydroxy ethyl)-m-chloroaniline;

$\mathrm{g}=N, N$-Bis(2-cyano ethyl)-m-toluidine; $\mathrm{h}=N$-(2-Hydroxy ethyl)aniline;

$\mathrm{i}=N$-Ethyl- $N$-(2-hydroxy ethyl)aniline; $\mathrm{j}=N, N$-Bis(acetoxy ethyl)aniline;

$\mathrm{k}=N$-(2-Cyano ethyl) aniline; $\mathbf{l}=N$-Methyl- $N$-cyanoethylaniline;

$\mathrm{m}=N$-(2-Hydroxy ethyl)-m-toluidine; $\mathrm{n}=N$-Methyl- $N$-(2-hydroxy ethyl)aniline;

$\mathrm{o}=N, N$-Bis(acetoxy ethyl)-m-chloroaniline.

150<smiles>[X]c1ccc(N2C(=O)c3ccc4c5ccc6c7c(ccc(c8ccc(c3c48)C2=O)c75)C(=O)N(c2ccc([X])cc2)C6=O)cc1</smiles>

$\mathrm{X}=\mathrm{H}, \mathrm{CH}_{3}, \mathrm{Cl}$ 151

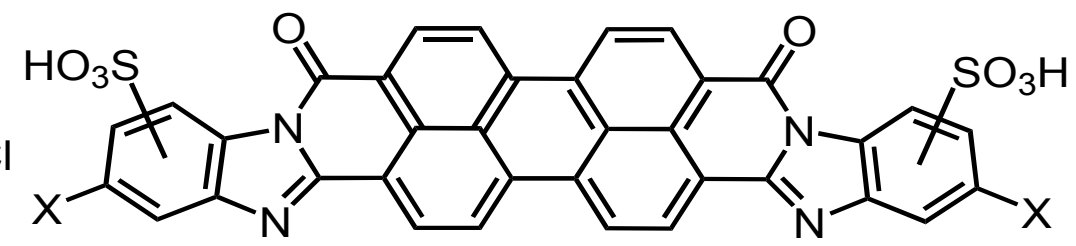<smiles>[R7]N=Nc1n[nH]c2nc([R])c(C#N)c(C)c12</smiles>

152<smiles>[R17]N=c1/c(=N/N=[R15])c2nc(NCC)c(C#N)c(C)c12</smiles>

$\mathrm{R}=\mathrm{Cl}, \mathrm{Et}_{2} \mathrm{~N} ; \mathrm{R}_{1}=4-\left(\mathrm{CH}_{3}\right)_{2} \mathrm{NC}_{6} \mathrm{H}_{4}, 2-\mathrm{CH}_{3} \mathrm{C}_{6} \mathrm{H}_{3}$ 
<smiles>[R]c1nc2[nH]nc(N=[W])c2c(C)c1C#N</smiles>

154<smiles>[R3]c1c(C)c(O)n([R2])c(=O)c1[R4]</smiles><smiles>[R5]c1cc(N([R6])[R])c([R6])cc1C</smiles>

$\mathrm{D}=\mathrm{Q}_{1}, \mathrm{Q}_{2}$, phenolic moiety; $\mathrm{R}_{1}=\mathrm{Cl}$, phenoxy,; $\mathrm{R}_{3}=\mathrm{CN}, \mathrm{C}_{1-4}$ alkyl sulfonyl $\mathrm{R}_{4}=$ alkyl, $\mathrm{Ph} ; \mathrm{R}_{5}=\mathrm{Cl}, \mathrm{CN} ; \mathrm{R}_{6}=\mathrm{H}, \mathrm{OCH}_{3}, \mathrm{OCH}_{2} \mathrm{CH}_{3} ; \mathrm{R}_{6}, \mathrm{R}_{7}=\mathrm{H}$

Fig.4. Chemical structure of pyrazolopyridine dyes.

$$
\mathrm{R}_{1}=\text { phenyl; } \mathrm{R}_{2}=\mathrm{CN} \text {, carbomoyl, } \mathrm{CO}_{2} \mathrm{H} ; \mathrm{R}_{3}=\mathrm{H}, \mathrm{NH}_{2}
$$

Fig.5. Chemical structure of dye 155.

Pyrazolopyridine dyes 154 (Fig. 4) were synthesized by diazotization of pyrazolo[3, 4-b] pyridine and azo-coupling with $\mathrm{H}$-acid. Dyestuffs 154 were suitable for dyeing synthetic fibers especially polyester and polyamide in fast yellow shade [80].

Diazotization of 4-nitroaniline and coupling with 6-cyano-2-heptadecyl-7-hydroxy-5methyl $[1,2,4]$ triazolo[1, 5-a]pyridine, gave dye 155 with yellow shade on polyester [81] (Fig. 5).

Water soluble dyes 156 was prepared by diazotizing 2, -dichlorosulfonilate and azocoupling with 2, 5-dimethyl-7-aminopyrazolo[1, 5-a]pyrimidine. Dyes 156 were employed for dyeing polyamide in yellow to orange shades and good fastness to wash and light [82] (Scheme 30).

Mono and disazo pyrazolo[3, 4- $b]$ pyridine acid dyestuffs $\mathbf{1 5 7}$ are practical for dyeing polyamide fibers in fast yellow shade. The acid dyes 157 were synthesized by diazotization of 3-amino5-cyano-4-methyl-6-(3-sulfophenylamino)$1 H$-pyrazolo[3, 4-b]pyridine and coupling with $N$-methyl-4-methyl-5-cyano-2-hydroxy-6pyridone [83] (Scheme 31).
Dicationic disazo dyes $\mathbf{1 5 8}$ were synthesized by azo-coupling two moles of 5-amino-1, 2, 3-trimethylbenzimidazoliummethylsulfate diazonium salt with $\mathrm{PhNEtCH}_{2} \mathrm{CH}_{2} \mathrm{NEtPh}$. Dyes 158 provided orange to reddish-orange shades on acrylic with good colorfastness properties and high color yield [3] (Scheme 30).

Water insoluble dyes 159 were prepared by azo-coupling of 2-butoxyethyl $p$-aminobenzoate diazonium salt with 2, 4-dihydroxy-quinoline (Scheme 31). Dyes 159 were used for dyeing polyester fibers [3].

Elnagdi et al. [84-86] reported the synthesis of enaminonitrile (piperidinylacrylonitrile) 160 which was reacted with aromatic diazonium salts to afford the corresponding arylhydrazones 161. Recently Khattab et al. [24, 87] reported the conversions of such arylhydrazones 161 into arylazoaminopyrazole disperse dyes 162 (Scheme 32). The synthesis and coloration performance of the fused heterocyclic arylazopyrazolopyrimidine 163 disperse dyes starting from their corresponding arylazoaminopyrazole 162 (Scheme 31).

The arylhydrazonopropanals 161 were reacted with 162 to afford isomeric products that may be 
formed as $\mathbf{1 6 3}$ or its isomeric form 164. Structure 163 was preferred because of their synthesis via coupling 165 with aromatic diazonium salts. Compound $\mathbf{1 6 5}$ in turn was synthesized via reaction of 162 with 160 (Scheme 31).

Only symmetrical derivatives of bisarylazopyrazolo[1,5-a]pyrimidin-7-ylamines $\mathbf{1 6 3}$ were synthesized in direct one-pot process via reacting 2:1 moles of the arylhydrazonopropanal 161 with hydrazine hydrate, respectively, for 5-6 hours in refluxing ethanol (Scheme 32).

Aminopyrazoles 162 were allowed to react with ethyl acetoacetate $\mathbf{1 6 6}$ to produce pyrazolo[1,5-a] pyrimidin-7-ones 167, while upon reaction of 162 with ethyl 3-arylhydrazonoacetoacetate 168 afforded the corresponding arylazopyrazolo[1,5-a]pyrimidin-7-ones 169 (Scheme 33).

Compound 171 was also coupled with the pyrazolediazonium chloride $\mathbf{1 7 0}$ to yield the pyrazolo[5,1-c] triazines $\mathbf{1 7 3}$. Trials to isolate the acyclic intermediate $\mathbf{1 7 2}$ were failed due to the direct formation of the triazine $\mathbf{1 7 3}$ as a result of cycloaddition reaction of the diazo compound $\mathbf{1 7 0}$ to $\beta$-naphthol 171 to introduce 172, which was then condensed and aromatized into 173 (Scheme 34).<smiles>[R2]c1cc([R2])n2nc(C)c(N=[W])c2n1</smiles>

$\mathrm{R}=2,4,5-\mathrm{Cl}_{2}\left(\mathrm{NaO}_{3} \mathrm{~S}\right) \mathrm{C}_{6} \mathrm{H}_{2} ; \mathrm{R}_{1}=\mathrm{CH}_{3} ; \mathrm{R}_{2}=\mathrm{NH}_{2}$

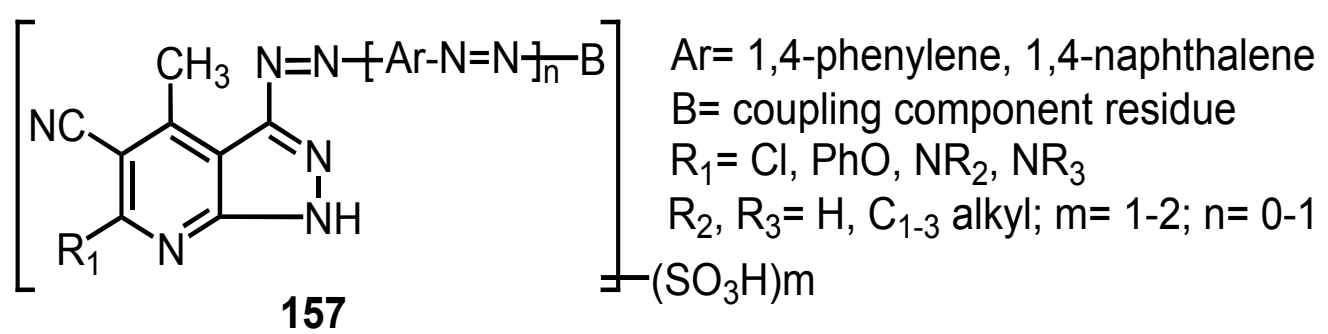<smiles>[R]Nc1ccc(N=Nc2ccc3c(c2)n(C)c(C)[n+]3C)cc1</smiles>

$\mathrm{R}=\mathrm{CH}_{2} \mathrm{CH}_{3} ; \mathrm{A}=\mathrm{CH}_{3} \mathrm{SO}_{4}$<smiles>[R]OC(=O)c1ccc(N=Nc2c(O)nc3ccccc3c2O)c([R16])c1</smiles>

$\mathrm{R}=\mathrm{Bu}, \mathrm{OCH}_{2} \mathrm{CH}_{2} ; \mathrm{R}_{1}=\mathrm{H}$

Scheme 31 


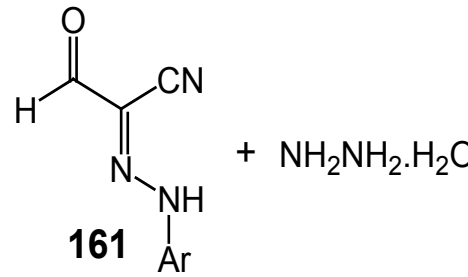

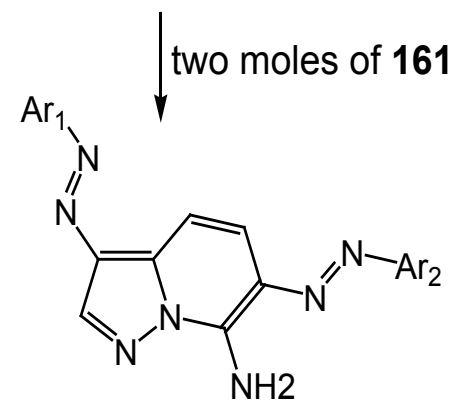

$163 \mathrm{Ar}_{1}=\mathrm{Ar}_{2}$

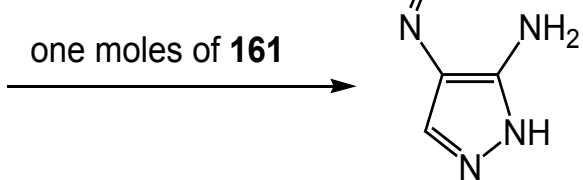

162 one moles of 161

$$
A r_{1}=A r_{2} \text { or } A r_{1} \# A r_{2}
$$

163a, $\mathrm{Ar}_{1}=\mathrm{C}_{6} \mathrm{H}_{5}, \mathrm{Ar}_{2}=\mathrm{C}_{6} \mathrm{H}_{4} \mathrm{NO}_{2}-\mathrm{p}$

163b, $\mathrm{Ar}_{1}=\mathrm{C}_{6} \mathrm{H}_{4} \mathrm{NO}_{2}-\mathrm{O}, \mathrm{Ar}_{2}=\mathrm{C}_{6} \mathrm{H}_{4} \mathrm{NO}_{2}-\mathrm{O}$

163c, $\mathrm{Ar}_{1}=\mathrm{C}_{6} \mathrm{H}_{5}, \mathrm{Ar}_{2}=\mathrm{C}_{6} \mathrm{H}_{4}$

163d, $\mathrm{Ar}_{1}=\mathrm{C}_{6} \mathrm{H}_{4} \mathrm{NO}_{2}-p, \mathrm{Ar}_{2}=\mathrm{C}_{6} \mathrm{H}_{4} \mathrm{NO}_{2}-p$

163e, $\mathrm{Ar}_{1}=\mathrm{C}_{6} \mathrm{H}_{4} \mathrm{CH}_{3}-p, \mathrm{Ar}_{2}=\mathrm{C}_{6} \mathrm{H}_{4} \mathrm{CH}_{3}-p$

Scheme 32<smiles>CCOC(=O)C(=NNC(C)(C)C)C(=O)OCC</smiles>

\section{$169 a-b$}

169a, $\mathrm{Ar}_{1}=\mathrm{C}_{6} \mathrm{H}_{4} \mathrm{NO}_{2}-p, \mathrm{Ar}_{2}=\mathrm{C}_{6} \mathrm{H}_{5}$

169b, $\mathrm{Ar}_{1}=\mathrm{C}_{6} \mathrm{H}_{4} \mathrm{NO}_{2}-p, \mathrm{Ar}_{2}=\mathrm{C}_{6} \mathrm{H}_{4} \mathrm{NO}_{2}-p$ 
<smiles>Nc1[nH]ncc1/N=N/[Al]</smiles>

162

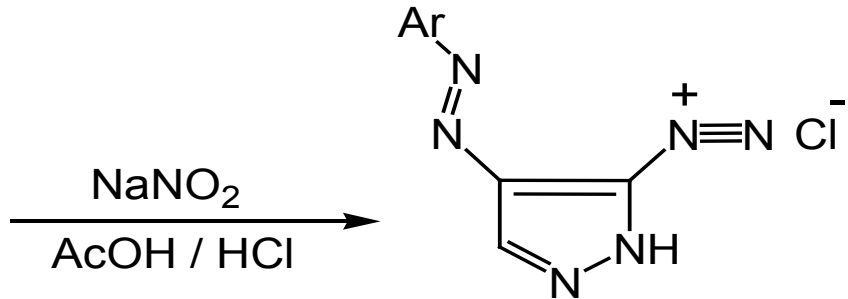

170<smiles></smiles>

The produced disperse colorants $\mathbf{1 6 2}, \mathbf{1 6 3}, \mathbf{1 6 5}$, 167 and 169 were applied on polyester fabrics to give, in general, satisfactory results. Such series of 4-arylazo-2H-pyrazol-3-ylamines, arylazopyrazolo[1,5-a]pyrimdin-7-ylamines and arylazopyrazolo[1,5-a]pyrimidin-7-ones disperse dyes gave yellow, orange to orange-red shades on polyester fabrics with satisfactory levelness, high depth of shade, and very good colorfastness to light, rubbing, perspiration and washing [24, 87].

\section{Conclusion}

Heteroaromatic dyestuffs are commonly commercialized to create a full range of dyestuff for coloration of textile fibers. The synthesis and application of fused nitrogen-containing heterocyclic dyestuffs for textile fibers have been widely investigated. Many derivatives of this category of compounds were confirmed to be excellent dyestuffs. We presented a systematic review of recently prepared fused nitrogencontaining heterocycles as dyes and their dyeing efficiency on a variety of textile fibers.

\section{References}

1. Shindy H.A., Synthesis of Different Classes of Five/Five Membered Heterocyclic Cyanine Dyes: A Review Paper. Mini-Reviews in Organic Chemistry; 9(2), 209-22 (2012).

2. Khattab T.A., Tiu B.D.B., Adas S., Bunge S.D., Advincula R.C., Solvatochromic, thermochromic and pH-sensory DCDHF-hydrazone molecular switch: response to alkaline analytes. RSC Advance; 6(104), 102296-305 (2016).

3. Hunger K., Industrial Dyes: Chemistry, Properties, Applications: John Wiley \& Sons (2007)

4. Khattab T.A., Novel solvatochromic and halochromic sulfahydrazone molecular switch. Journal of Molecular Structure; 1169, 96-102 (2018).

5. Zollinger H., Color Chemistry: Syntheses, Properties, and Applications of Organic Dyes and Pigments: John Wiley \& Sons, (2003).

6. Khattab T.A., Rehan M., Hamouda T., Smart textile framework: Photochromic and fluorescent cellulosic fabric printed by strontium aluminate pigment. Carbohydrate Polymers; 195, 143-52 (2018).

7. Abdelmoez S., El Azeem A., Rehab A., Nada A.A.,

Egypt. J. Chem. 61, No.6 (2018) 
Khattab T.A., Electrospun PDA-CA Nanofibers toward Hydrophobic Coatings. Zeitschrift für Anorganische und Allgemeine Chemie; 642(3), 219-21 (2016).

8. Khattab T.A., Rehan M., Aly S.A., Hamouda T., Haggag K.M., Klapötke T.M., Fabrication of PANTCF-hydrazone nanofibers by solution blowing spinning technique: Naked-eye colorimetric sensor. Journal of Environmental Chemical Engineering; 5(3), 2515-23 (2017).

9. Abou-Yousef H., Khattab T.A., Youssef Y.A., AlBalakocy N., Kamel S., Novel cellulose-based halochromic test strips for naked-eye detection of alkaline vapors and analytes. Talanta; 170, 137-45 (2017).

10. Khattab T.A., Gaffer H.E., Aly S.A., Klapötke T.M., Synthesis, Solvatochromism, Antibacterial Activity and Dyeing Performance of Tricyanofuran-Hydrazone Analogues. Chemistry Select; 1(21), 6805-9 (2016).

11. Khattab T.A., Gaffer H.E., Synthesis and application of novel tricyanofuran hydrazone dyes as sensors for detection of microbes. Coloration Technology; 132(6), 460-5 (2016).

12. Saini A., Christenson C., Khattab T., Wang R., Twieg R., Singer K., Threshold response using modulated continuous wave illumination for multilayer 3D optical data storage. Journal of Applied Physics; 121(4), 043101 (2017).

13. [13] Khattab T.A., Tiu B.D.B., Adas S., Bunge S.D., Advincula R.C., $\mathrm{pH}$ triggered smart organogel from DCDHF-Hydrazone molecular switch. Dyes and Pigments; 130, 327-36 (2016).

14. Khattab T.A., Abdelmoez S., Klapötke T.M., Electrospun Nanofibers from a TricyanofuranBased Molecular Switch for Colorimetric Recognition of Ammonia Gas. Chemistry-A European Journal; 22(12), 4157-63 (2016).

15. Khattab T.A., Synthesis and Self-assembly of Novel s-Tetrazine-based Gelator. Helvetica Chimica Acta; 101(4), e1800009 (2018).

16. Elewa S.I., Mohamed M.G., Synthesis and study antimicrobial activities of some novel Tetrazole derivatives. Egyptian Journal of Chemistry; 61(1), 90-100 (2018).

17. Othman H.S., Al-Hashash M., Nawwar GAE-M., Cyanoacetyl urea in heterocyclic synthesis part V: Facile synthesis of poly-functionalized pyrimdines via different behaviors of its free urea amino group. Egyptian Journal of Chemistry; 61(1), $207-$ 12 (2018).

18. Hafez H.N., Microwave-Assisted Synthesis and Cytotoxicity Evaluation of Some Novel Pyrazole Containing Imidiazoles, Pyrazoles, Oxazoles, Thiadiazoles and Benzochromene Derivatives. Egyptian Journal of Chemistry; 60(6), 1015-28 (2017).

19. Mahmoud M., Abdelwahab S.S., Saied K., Synthesis of Novel 2, 3-Disubstituted Quinazolin4- $(3 \mathrm{H})$-ones and Their Antibacterial Activity on the Ultra-structure of Some Pathogenic Microorganisms. Egyptian Journal of Chemistry; 60(6), 1059-66 (2017).

20. El-Sawy E., Abo-Salem H., Mandour A., 1H-Indole-3-carboxaldehyde: Synthesis and Reactions. Egyptian Journal of Chemistry; 60(5), 723-51(2017).

21. Rizk S., Attia S., Osman D.I., Nessim M., Synthesis and Applications of Pyridazinones for Base Oil Improvement. Egyptian Journal of Chemistry; 60(1), 129 (2017).

22. Anderson R., Nickless G., Heterocyclic azo dyestuffs in analytical chemistry. A review. Analyst; 92(1093), 207-38 (1967).

23. Luo S., Zhang E., Su Y., Cheng T., Shi C., A review of NIR dyes in cancer targeting and imaging. Biomaterials; 32(29), 7127-38 (2011).

24. Khattab T.A., Elnagdi M.H., Haggaga K.M., Abdelrahmana A.A., Abdelmoez Aly S., Green Synthesis, Printing Performance, and Antibacterial Activity of Disperse Dyes Incorporating Arylazopyrazolopyrimidines. AATCC Journal of Research; 4(4), 1-8 (2017).

25. Strekowski L., Heterocyclic Polymethine Dyes: Synthesis, Properties and Applications: Springer, (2008).

26. Gaffer H., Khattab T., Synthesis and characterization of some azo-heterocycles incorporating pyrazolopyridine moiety as disperse dyes. Egyptian Journal of Chemistry; 60, 41-7 (2017).

27. Elapasery M., Shakra S., Abbas D., Gaffer H., Allam E., Synthesis of some azo disperse dyes based on pyridone moiety and their application on polyester fabrics. Egyptian Journal of Chemistry; 60, 97-102 (2017).

28. EL-Hashash M., Rizk S., Kadhim M., Facile Egypt. J. Chem. 61, No.6 (2018) 
Synthesis and Structural Characterization of Some Phthalazin-1 (2H)-one Derivatives as Antimicrobial Nucleosides and Reactive Dye. Egyptian Journal of Chemistry; 60(3), 407-20 (2017).

29. Aliwarga H., Hallas G., Synthesis and electronic spectra of some azo disperse dyes derived from $\mathrm{N}-2$, 2, 2-trifluoroethyl-1, 2, 3, 4-tetrahydroquinoline. Dyes and Pigments; 2(3), 195-203 (1981).

30. Grecu R., Pieroni M., Carpignano R., Quantitative relationships between chemical structure and technical properties of arylazoindole sulphonic acid dyes. Dyes and Pigments; 2(4), 305-18 (1981).

31. Carlini F.M., Paffoni C., Boffa G., New daylight fluorescent pigments. Dyes and Pigments; 3(1), 59-69 (1982).

32. Ayyangar N., Lahoti R., Otiv S., Disperse dyes derived by the condensation of homophthalimides and 2-pyridones with naphthostyril and isatin. Dyes and Pigments; 3(4), 317-24 (1982).

33. Shekar P., Seshadri S., A novel synthesis of anthraquinone $[1,2-b]$ pyrroles and their conversion to 1-amino-2-benzoylanthraquinone derivatives. Dyes and Pigments; 5(4), 277-84 (1984).

34. Peters A., Bide M., Amino derivatives of 1 , 8-naphthalic anhydride and derived dyes for synthetic-polymer fibres. Dyes and Pigments; 6(5), 349-75 (1985).

35. Peters A., Bide M., Phenylazo derivatives of 1 , 8-naphthalimides and of 7H-benzimidazo (2, 1-a) benz $(\mathrm{d}, \mathrm{e})$ isoquinolin-7-ones: dyes for synthetic polymer fibres. Dyes and Pigments; 7(4), 237-47 (1986).

36. Krishnan R., Sekar N., Seshadri S., Studies on the use of 7-Amino-3-(4-aminophenyl) quinoline as a benzidine substitute. Dyes and Pigments; 7(6), 457-65 (1986).

37. Lawrance W.A., Friedel and crafts'reaction-nitrophthalic anhydrides and acetylamino-phthalic anhydrides with benzene and aluminum chloride. Journal of the American Chemical Society; 42(9), 1871-9 (1920).

38. Bogert M.T., Boroschek L., Some experiments with the mononitroortho-phthalic acids. Journal of the American Chemical Society; 23(10), 740-61 (1901).
39. Scott J.R., Cohen J.B., LXXI.-On some carbamido-acids and their hydantoins. Journal of the Chemical Society, Transactions; 119, 664-72 (1921).

40. Bogert M.T., Renshaw R.R., 4-AMINO-oPHTHALIC ACID AND SOME OF ITS DERIVATIVES. Journal of the American Chemical Society; 30(7), 1135-44 (1908).

41. Rangnekar D., Rajadhyaksha D., Synthesis of phthalimid-3-yl and-4-yl aminoethylenes and pyrroloquinolines and a study of their fluorescence properties. Dyes and Pigments; 8(1), 1-10 (1987).

42. Rangnekar D., Tagdiwala P., Synthesis of azo dyes from 6-amino-2-methoxy-quinoxaline and their use as disperse dyes for polyester fibres. Dyes and Pigments; 8(2), 151-6 (1987).

43. Moeckli P., Preparation of some new red fluorescent 4-cyanocoumarin dyes. Dyes and Pigments; 1(1), 3-15 (1980).

44. Gokhale U., Seshadri S., Synthesis of 1, 2-fused benzimidazo heterocycles from benzimidazole2-acetonitrile and heterocyclic orthochloroaldehydes. Dyes and Pigments; 8(2), 157 63 (1987).

45. Srinivasan K., Seshadri S., Synthesis of disperse dyes derived from 1-Cyano-2-substituted-3azabenzanthrones. Dyes and Pigments; 8(3), 22530 (1987).

46. Vaidyanathan A., Sunthankar S., cellulose acetate dyes. 8. Synthesis of thraquinonylamino methyleneacetoacetates +4 ]-hydroxy-3]-acetylpyridinoanthraquinones. Indian Journal of Technology; 2(2), 56 (1964).

47. Ayyangar N., Lahoti R., Otiv S., Srinivasan K., Polycyclic Compounds. Part V: Reaction of Aminoanthraquinones with $\alpha, \beta$-Unsaturated Carbonyl Compounds; Synthesis of Disperse Dyes for Polyester. Dyes and Pigments; 8(5), 33543 (1987).

48. Haskell T.H., Peterson F.E., Watson D., Plessas N.R., Culbertson T., Neuraminidase inhibition and viral chemotherapy. Journal of Medicinal Chemistry; 13(4), 697-704 (1970).

49. Garmaise D., Komlossy J., The preparation of 2-arylimidazo $[4,5-\mathrm{b}]$ pyridines. The Journal of Organic Chemistry; 29(11), 3403-5 (1964).

50. Tretyakov A., Rudaya L., El'tsov A., Larin M., Lopyrev V., Carbon-13 NMR spectra of isomeric 
2-arylimidazopyridines. Magnetic Resonance in Chemistry; 23(1), 7-9 (1985).

51. Savarino P., Viscardi G., Barni E., Carpignano R., Heterocyclic monoazo dyes for polyamide, derived from 4-alkylamido-2-hydroxybenzoic acids. Dyes and Pigments; 9(4), 295-304 (1988).

52. Barni E., Savarino P., di Modica G., Carpignano R., Papa S.S., Giraudo G. Monoazo dyes for polyamide derived from 4-alkylamido-2hydroxybenzoic acids. Dyes and Pigments; 5(1), 15-36 (1984).

53. Spector R.H., Joullie M.M., 1, 2, 3-Benzotriazines. III. the synthesis of pyrido [2', 2'(3', 2'): 4, 5] imidazo $[1,2-c][1,2,3]$ benzotriazine and pyrido $\left[3^{\prime}, 4^{\prime}\left(4^{\prime}, 3^{\prime}\right): 4,5\right]$ imidazo $[1,2-c][1,2,3]$ benzotriazine. Journal of Heterocyclic Chemistry; 5(2), 301-2 (1986).

54. Dhamnaskar S., Rangnekar D., Synthesis of triazoflo [4, 5-b] pyrido [1', 2'-a] benzimidazole derivatives as fluorescent disperse dyes and whiteners for polyester fibre. Dyes and Pigments; 9(6), 467-73 (1988).

55. Savarino P., Viscardi G., Carpignano R., Barni E., Ferrero G., Disperse and cationic dyes derived from 2-(meta-and para-Aminophenyl) imidazo [4, 5-b] pyridine. Dyes and Pigments; 10(2), 97-110 (1989).

56. Backeberg O., Staskun B., A novel reduction of nitriles to aldehydes. Journal of the Chemical Society (Resumed); 3961-3 (1962).

57. Shenoy V., Seshadri S., Synthesis of benzimidazo-[1, 2-a]-quinolines: fluorescent disperse dyes. Dyes and Pigments; 11(2), 137-45 (1989).

58. Savarino P., Viscardi G., Carpignano R., Barni E., Ferrero G., Disperse and cationic dyes from aminophenyl-X-azolo-pyridines. Dyes and Pigments; 11(3), 163-72 (1989).

59. Galil F.M.A., Khalifa F.A., Abdin T.S., Synthesis and dyeing characteristics of some new asymmetrical 3-cyanoformazans. Dyes and Pigments; 12(1), 49-56 (1990).

60. Rangnekar D., Dhamnaskar S., Synthesis of 5-hetarylpyrazolo [3, 4-b] pyrazines and their use as disperse dyes for polyester fibres. Dyes and Pigments; 13(4), 241-50 (1990).

61. Naik D., Desai K., Heterocyclic monoazo dyes derived from 4-oxoquinazoline. Dyes and Pigments; 14(1), 1-7 (1990).

62. Szadowski J., Disazo direct dyes containing cyclic amido, keto and amino groups. Dyes and Pigments; 14(3), 217-24 (1990).

63. Rajagopal R., Seshadri S., Synthesis of new fluorescent dyes from 6-methoxy-1-chloro-3, 4-dihydronaphthalene-2-carboxaldehyde. Dyes and Pigments; 17(1), 57-69 (1991).

64. Viscardi G., Savarino P., Barni E., Quagliotto P., Di Modica G., Botta M., Disperse and cationic azo dyes from heterocyclic intermediates. Dyes and Pigments; 19(1), 69-79 (1992).

65. Clark R.L., Pessolano A.A., Synthesis of some substituted benzimidazolones. Journal of the American Chemical Society; 80(7), 1657-62 (1958).

66. Newbold G., Spring F., The oxidation of 2-hydroxyquinoxaline and its derivatives with hydrogen peroxide. Journal of the Chemical Society (Resumed); 519-23 (1948).

67. Levy L.F., Stephen H., CXXIII.-4-Aminophthalide and some derivatives. Journal of the Chemical Society (Resumed); 867-71 (1931).

68. Drew H., Pearman F., Chemiluminescent organic compounds. Part II. The effect of substituents on the closure of phthalhydrazides to 5-and 6-membered rings. Journal of the Chemical Society (Resumed); 26-33 (1937).

69. Szadowski J., Niewiadomski Z., Direct dyes containing cyclic amide groups. Dyes and Pigments; 21(2), 123-33 (1993).

70. Dashevsky M., Acenaphthene Moscow. Khimiya Publishers; (1966).

71. David H.E.F., Grundlegende Operationen Der Farben Chemie: Springer-Verlag, (1952).

72. Konstantinova T., Meallier P., Grabchev I., The synthesis of some 1, 8-naphthalic anhydride derivatives as dyes for polymeric materials. Dyes and Pigments; 22(3), 191-8 (1993).

73. Klosa J., Synthese von 2, 3-substituierten Chinazolon-(4)-derivaten mit Hilfe von Phosphoroxychlorid. Advanced Synthesis \& Catalysis; 14(1-2), 84-98 (1961).

74. Errede L., Oien H., Yarian D., Acylanthranils. 3. The influence of ring substituents on reactivity and selectivity in the reaction of acylanthranils with

Egypt. J. Chem. 61, No.6 (2018) 
amines. The Journal of Organic Chemistry; 42(1), 12-8 (1977).

75. Patel V.H., Patel M.P., Patel R.G., Fused heterocycle 11-amino-13H-acenaphtho [1, 2-e] pyridazino [3, 2-b] quinazoline-13-one based monoazo disperse dyes. Dyes and Pigments; 52(3), 191-8 (2002).

76. Patel K.M., Patel V.H., Patel M.P., Patel R.G., Monoazo disperse dyes derived from 11H-7amino-2-chloro-isoindolo [2, 1-a] benzimidazole11-one. Dyes and Pigments; 55(1), 53-8 (2002).

77. Hallas G., Zhai K., Synthesis and electronic spectra of some azo disperse dyes derived from N-alkyl-1, 2, 3, 4-tetrahydroquinoline. Dyes and Pigments; 32(4), 187-92 (1996).

78. Zollinger H., Synthesis, properties and applications of organic dyes and pigments. Colour Chemistry. New York: John Wiley-VCH Publishers; (2002).

79. Wojciechowski K., Wolska A., Substantivity and spatial structure of soluble polycyclic dyes for dyeing cellulose fibres. Dyes and Pigments; 65(2), 111-6 (2005).

80. Akahori K., Miki M., Omura T., Harada N., Washimi T., Monoazo red reactive dye compound having a vinylsulfone type fiber reactive group and a substituted triazinyl group. Google Patents; (1992).

81. Hansen G., Lamm G., Reichelt H., Schefczik E., Thiazoleazo dyes having a diazo component from the isothiazole or thiadiazole series. Google Patents; (1992).
82. Ridyard D.R.A., Renfrew AHM. Amine pyrazole nickel phthalocyanine dyes for coloration. Google Patents; (2001).

83. Hahn W., Muszynski M., Disperse dyes derived from 3-arylazo-5-cyano-4-methyl-1H-pyrazolo [3, 4-b] pyridine. Chem Stosow; 30(3), 421-9 (1986).

84. Abdelhamid I.A., Nasra M.A., Elnagdi M.H., Chemistry of 2-arylhydrazonals. Synlett; 2009(20), 3237-51 (2009).

85. Khattab T., Haggag K.M., Synthesis and spectral properties of symmetrical and asymmetrical 3-cyano-1, 5-diarylformazan dyestuffs for dyeing polyester fabrics. Egyptian Journal of Chemistry; 60, 33-40 (2017).

86. Moustafa M., Al-Mousawi S., El-Seedi H., Elnagdi M., Chemistry of Heterocyclic Five and Six Membered Enamino Nitriles and Enamino Esters. Mini Reviews in Medicinal Chemistry; (2016).

87. Khattab T.A., Haggag K.M., Elnagdi M.H., AbdelrahmanA.A.,AbdelmoezAly S., MicrowaveAssisted Synthesis of Arylazoaminopyrazoles as Disperse Dyes for Textile Printing. Zeitschrift für anorganische und allgemeine Chemie; 642(13), 766-72 (2016).

(Received 11/6/2018; accepted 9/7/2018)

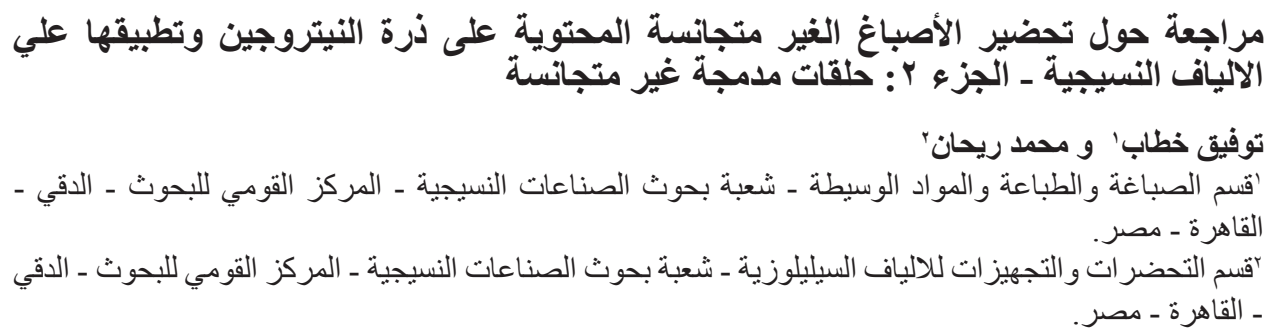

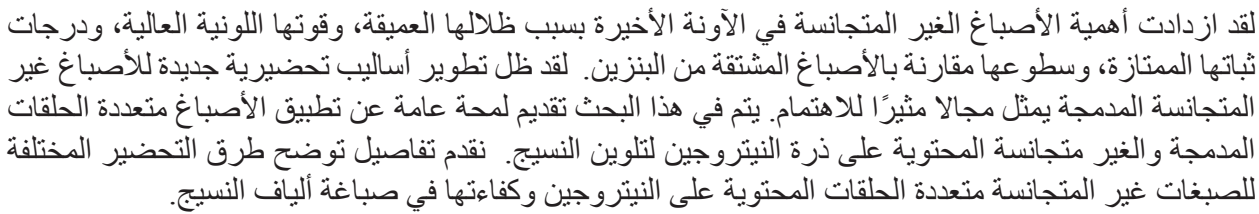

Egypt. J. Chem. 61, No.6 (2018) 